\title{
Satellite Measured Ionospheric Magnetic Field Variations over Natural Hazards Sites
}

\author{
Christoph Schirninger ${ }^{1,+}$, Hans U. Eichelberger ${ }^{1, *,+}$, Werner Magnes ${ }^{1} \mathbb{D}$, Mohammed Y. Boudjada ${ }^{1,+}{ }^{,}$ \\ Konrad Schwingenschuh ${ }^{1,+}$, Andreas Pollinger ${ }^{1}$, Bruno P. Besser ${ }^{1}$, Pier F. Biagi ${ }^{2}{ }^{\oplus}$, Maria Solovieva ${ }^{3}$, \\ Jindong Wang ${ }^{4}$, Bingjun Cheng ${ }^{4}$, Bin Zhou ${ }^{4}$, Xuhui Shen ${ }^{5}$, Magda Delva ${ }^{1}$ and Roland Lammegger ${ }^{6}$
}

Citation: Schirninger, C.;

Eichelberger, H.U.; Magnes, W.; Boudjada, M.Y.; Schwingenschuh, K.; Pollinger, A.; Biagi, P.F.; Solovieva, M.; Wang, J.; Cheng, B.; et al. Satellite Measured Ionospheric Magnetic Field Variations over Natural Hazards Sites Remote Sens. 2021, 13, 2360. https:// doi.org/10.3390/rs13122360

Academic Editors: Christopher Gomez, Candide Lissak and Danang Sri Hadmoko

Received: 9 April 2021

Accepted: 9 June 2021

Published: 17 June 2021

Publisher's Note: MDPI stays neutral with regard to jurisdictional claims in published maps and institutional affiliations.

Copyright: (c) 2021 by the authors. Licensee MDPI, Basel, Switzerland. This article is an open access article distributed under the terms and conditions of the Creative Commons Attribution (CC BY) license (https:/ / creativecommons.org/licenses/by/ $4.0 /)$.
1 Space Research Institute, Austrian Academy of Sciences, Schmiedlstraße 6, 8042 Graz, Austria; Christoph.Schirninger@oeaw.ac.at (C.S.); Werner.Magnes@oeaw.ac.at (W.M.); Mohammed.Boudjada@oeaw.ac.at (M.Y.B.); Konrad.Schwingenschuh@oeaw.ac.at (K.S.);

Andreas.Pollinger@oeaw.ac.at (A.P.); Bruno.Besser@oeaw.ac.at (B.P.B.); Magda.Delva@oeaw.ac.at (M.D.)

2 Department of Physics, University of Bari, 70126 Bari, Italy; pf.biagi@gmail.com

3 Schmidt Institute of Physics of the Earth, Russian Academy of Sciences, 123995 Moscow, Russia; MCSolovieva@gmail.com

4 National Space Science Center, Chinese Academy of Sciences, Beijing 100190, China; wjd@nssc.ac.cn (J.W.); chengbj@nssc.ac.cn (B.C.); zhoubin@nssc.ac.cn (B.Z.)

5 National Institute of Natural Hazards, MEMC, Beijing 100085, China; xuhuishen@ninhm.ac.cn

6 Institute of Experimental Physics, Graz University of Technology, 8010 Graz, Austria;

Roland.Lammegger@tugraz.at

* Correspondence: hue@oeaw.ac.at

+ These authors contributed equally to this work.

Abstract: Processes and threats related to natural hazards play an important role in the evolution of the Earth and in human history. The purpose of this study is to investigate magnetic field variations measured at low Earth orbit (LEO) altitudes possibly associated with earthquakes, volcanic eruptions, and artificial outbursts. We focus on two missions with well equipped magnetometer packages, the China Seismo-Electromagnetic Satellite (CSES) and ESA's three spacecraft Swarm fleet. After a natural hazards survey in the context of this satellites, and consideration of external magnetospheric and solar influences, together with spacecraft interferences, wavelet analysed spatio-temporal patterns in ionospheric magnetic field variations related to atmospheric waves are examined in detail. We provide assessment of the links between specific lithospheric or near surface sources and ionospheric magnetic field measurements. For some of the diverse events the achieved statistical results show a change in the pattern between pre- and post-event periods, we show there is an increase in the fluctuations for the higher frequency (smaller scales) components. Our results are relevant to studies which establish a link between space based magnetic field measurements and natural hazards.

Keywords: CSES; Swarm; earthquake; volcano; natural hazards; ionosphere; atmospheric waves

\section{Introduction}

The broad context of this study is addressing the issues of space based magnetic field measurements in the frame of natural hazards investigations. The impacts on society of, e.g., volcanic eruptions or earthquakes could be severe and systematic action is of vital importance. The purpose and focal point of this work is on the advanced magnetic field observation capabilities of two space missions. These are the China Seismo-Electromagnetic Satellite (CSES; or Zhangheng-1, named after the Chinese polymath), a China National Space Administration (CNSA) and Italian Space Agency (ASI) collaboration, and ESA's Swarm mission, and how a synergy of different instruments can achieve a global space based picture of the mentioned threats. The satellites are equipped with a rich and strong portfolio of ambitious field- and plasma-packages for a wide range of scientific investigations, but the main aim of this work is a characterisation of natural lithospheric events primarily with 
the magnetic field in the key role, i.e., a single dominant physical parameter. In recent complementary efforts, a broad spectrum of satellite based observations had already an important contribution to the overall characterisation of these phenomena with the potential of a variety of societal benefits and applications [1].

\section{Magnetic Field Measurements at Low Earth Orbit Altitudes}

The scalar- and vector-magnetic field measurements are acquired from two low Earth orbit (LEO) missions around $500 \mathrm{~km}$ altitude with their respective instruments operating in the ionospheric F-region, CSES and the three Swarm satellites.

\subsection{CSES}

The main objective of CSES is the study of ionospheric responses to lithospheric processes, i.e., electromagnetic- and plasma-phenomena related to natural hazards, in particular earthquakes (EQ) with possibly precursor phenomena. The three axes stabilised spacecraft with eight scientific instruments was launched on 2 February 2018, into a sun synchronous polar orbit with an altitude of $\sim 507 \mathrm{~km}$ and an inclination of $97.4 \mathrm{deg}$ [2]. One of the instrument packages is the high precision magnetometer (HPM) consisting of two fluxgate magnetometer (FGM; FGM1 and FGM2) and a scalar coupled dark state magnetometer (CDSM). The HPM data processing pipeline includes corrections, interference mitigation, synchronisation, and calibration steps for the nominally sampled $60 \mathrm{~Hz}$ FGM vectors and $30 \mathrm{~Hz}$ CDSM values [3]. The science data cover the latitude range from -65 deg to +65 deg with a temporal resolution of $1 \mathrm{~s}$. The CDSM instrument is a scalar magnetometer based on two-photon spectroscopy and has a noise level of $\sim 50 \mathrm{pT} / \mathrm{sqrt}(\mathrm{Hz})$ at $1 \mathrm{~Hz}$, an accuracy of $0.19 \mathrm{nT}(1 \sigma)$, and a total magnetic field measurement range from $10^{3}$ $10^{5} \mathrm{nT}$ [4]. The HPM instruments are parallel aligned, from the satellite surface outwards in the layout FGM1-FGM2-CDSM, and mounted along a $4.7 \mathrm{~m}$ nadir pointing boom in order to minimise the spacecraft magnetic disturbances. In-orbit results with a performance analysis have been reported by [5], the CSES data description, and data service are detailed in [6].

\subsection{Swarm}

Swarm is an ESA mission (launched on 22 September 2013) consisting of three identical satellites in near-polar, circular orbits with the goal to study the Earth's magnetic field in all aspects. The implemented orbital constellation are two satellites closely spaced side-by-side (i.e., 1.4 deg longitudinal separation and only a few seconds differential delay

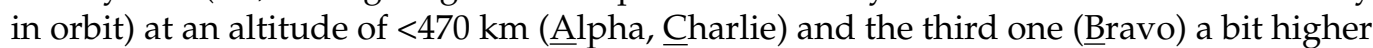
at $<520 \mathrm{~km}$ (altitude decrease during life time). The Level- $1 \mathrm{~b}$ magnetic field products are derived from two instruments, the absolute scalar magnetometer (ASM) and the vector field magnetometer (VFM) with $1 \mathrm{~Hz}$ data rates for both instruments (low rate) and in addition $50 \mathrm{~Hz}$ (high rate) for the VFMs. A detailed description, including nomenclature, ephemeris- and plasma-products together with derived Level-2 products is given by [7].

\subsection{Magnetic Field Models and Multi-Experiment Observations}

The generation of geomagnetic field models including secular variations is an important application of space based measurements to study long term behaviour in terms of month and timescales beyond, e.g., [8]. In case of distinct natural hazards we rely on observations immediately before and after the events. The time frame could be from a few weeks, days, up to hours-in any case as much as possible steady conditions-and also depends on the time of the preparation phase of an, e.g., earthquake. This implies, at first glance, that carrying out and comparing such models are not fully useful, narrow preand post-spatio-temporal high-quality samplings in multi experiment settings and complementary measurements are preferable $[9,10]$. The $1 \mathrm{~Hz}$ magnetic field data from CSES HPM permit the analysis of large scale structures, whereas the Swarm VFM $50 \mathrm{~Hz}$ high rate 
values enable the study of, e.g., fine structured details during boundary crossings in the ionosphere above target objects on the ground.

\section{Lithospheric Atmospheric Ionospheric Coupling}

Important scientific objectives are the couplings and energy carriers from solid earth sources up to ionospheric heights, the so-called lithospheric atmospheric ionospheric coupling (LAIC). This is in particular relevant if physically based short-term earthquake forecasting in the context of precursory signals of natural hazards shall be achieved, see [11] and references therein. Joint collaborative efforts in a multi-parameter approach shall facilitate early risk mitigation of this most of the time cascade of events and protect society and infrastructure. Simões et al. (2012) [12] gave a summary of these couplings in terms of electromagnetic waves, refs. [13-15] investigated precursory phenomena, the latter with Swarm data in respect of, e.g., precursor time versus main shock magnitude [16]. Marchetti et al. (2020) [17] conducted co-seismic investigations with Swarm magnetic field data, ref. [18] used magnetic field and electron density measurements in the analysis of large earthquakes.

\subsection{Earth-Ionosphere Waveguide}

The Earth-Ionosphere Waveguide extends from the surface (lower boundary) up to the lower ionosphere (upper boundary), which is the D-layer during daytime and the Elayer during night. The wave propagation between narrowband very low frequency (VLF; $\mathrm{f}=3-30 \mathrm{kHz}$ ) and low frequency $(\mathrm{LF} ; \mathrm{f}=30-300 \mathrm{kHz}$ ) transmitter and receiver stations is confined in this cavity, e.g., [19]. In a network configuration with several VLF/LF propagation paths it is possible to sample larger areas, e.g., over Southern Europe [20]. The upper waveguide boundary could be externally driven, e.g., through solar X-ray flares [21], but significant internal drivers can be acoustic waves (AW) and atmospheric gravity waves (AGW) [22]. A thorough and systematic understanding of phenomena up to the lower ionosphere is a basic requirement for investigations of the upper atmosphere (thermosphere) with decisive in-situ measurements. An important task is to systematically quantify uncertainties in the datasets and finally validate and verify the processes in accurate and predictive ways.

\subsection{Acoustic Waves and Atmospheric Gravity Waves}

The approach to delineate irregularities in the upper atmosphere with atmospheric gravity waves (AGW) including propagation effects along the channel from bottom to top is based on seminal work by [23]. Due to seismic events like earthquakes, volcanic eruptions or tsunamis, acoustic- and atmospheric gravity waves (internal waves; continuously stratified medium) are able to propagate upwards into the ionosphere. Therefore, they could generate oscillations in the ionospheric plasma. The governing equations of motion for adiabatic conditions including inertia-, gravity-, and pressure gradient forces are, see [24],

$$
\begin{array}{rr}
\text { continuity: } & \frac{\partial \rho}{\partial t}+\mathbf{v} \cdot \rho=-\rho \mathbf{v}, \\
\text { momentum: } & \frac{\partial \mathbf{v}}{\partial t}+\mathbf{v} \cdot \nabla \mathbf{v}=\mathbf{g}-\frac{1}{\rho} \nabla p, \\
\text { adiabaticity: } & \frac{\partial p}{\partial t}+\mathbf{v} \cdot \nabla p=C_{s}^{2}\left(\frac{\partial p}{\partial t}+\mathbf{v} \cdot \nabla p\right),
\end{array}
$$

where $\mathbf{v}$ corresponds to the neutral gas velocity, $\rho$ is the density, $p$ the pressure, $\mathbf{g}$ the gravitational acceleration, and $C_{S}$ the constant speed of sound. The dispersion relation, assuming harmonic processes, small perturbations, and linearised equations is:

$$
\left(\omega^{2}-\omega_{a}^{2}\right)+\left(\frac{\omega_{g}^{2}}{\omega^{2}}-1\right) k_{x}^{2} C_{s}^{2}-k_{z}^{\prime 2} C_{s}^{2}=0 .
$$


If the wave numbers $k_{x}$ and $k_{z}^{\prime}=k_{z}+i / 2 H$ are real, acoustic waves are determined with an angular frequency $\omega>\omega_{a}=\frac{\gamma g}{2 C_{s}}$ and internal atmospheric gravity waves with $\omega<\omega_{g}=\frac{(\gamma-1)^{1 / 2} g}{C_{s}}$. Here $\gamma$ corresponds to the ratio of the specific heat, $\omega_{a}$ is called the acoustic low frequency cut-off and $\omega_{g}$ the high frequency cut-off for internal gravity waves, the so-called Brunt-Väisälä frequency (buoyancy frequency). For upward propagation, because of the imaginary part of $k_{z}$, the amplitudes of these waves grow as $\exp (z / 2 H)$, where $H=\frac{C_{s}^{2}}{\gamma g}$ is the atmospheric scale height. Kinetic energy can be conserved while the exponential density losses are compensated at the same time, which means that the energy flux remains constant.

\section{Data Processing Method}

For a source event with specific date and geographical coordinate a virtual spatial box of usually a few degrees in lat/long is selected. If line of sight projected footprints from satellites are within this area, the magnetic field values from these orbit segments (transits of the area) are considered and selected for further processing. In general, these segments are crossings before and after the event, the extend of the time interval is selectable (usually a few days). All field components for each segment are individually detrended, this corresponds to a high-pass filtering with low corner frequency of $f_{c}=0.02 \times f_{N y}$, where $f_{N y}$ is the Nyquist frequency. A wavelet transform (Morse wavelet, symmetry $\gamma=3$, time-bandwidth product $P^{2}=60$ ) converts the components (time series) into a time-scale decomposition. With the absolute values of this representation a binning into frequency bands (scales) is conducted. For Swarm the statistics of the fluctuations are computed over the time dimension of the scalogram for each crossing, i.e., over the time shift for each scale of the wavelet transform (not over different crossings). In case of CSES HPM the segments before the event are merged to a single entity, a second entity are the merged segments after the event. This is necessary to get enough measurements for the further processing, i.e., a higher sample rate is preferable. For CSES HPM the step size is in log-scale according to $\ln \left(f_{n}\right)=-0.7651-0.069315 \times \mathrm{n}$, where $\mathrm{n}$ is the number of steps shown in the ranges $\mathrm{n}=\{1-$ 50, $1-60,1-63$, for Swarm A/B/C VFM the step size is $\ln \left(f_{n}\right)=3.1469-0.069315 \times \mathrm{n}$, shown are two ranges $n=\{1-40,1-61\}$. The significance of the values are higher at the lower end of the range (the higher frequencies), because the fluctuations are usually weak for the upper range but depending also on the strength of the source event. The statistics of the segment bands are compared. For the evaluation and graphical representation (box plots) median values and the $25 / 75$ percentiles are used, outliers are individually drawn, and the boxes/points are colour and shape coded. Segments before (after) the event are in blue (red) colour with fading intensity for larger time differences to the event time, i.e., focus is on crossings in the temporal vicinity of the event, notches indicate the medians. The widths of the boxes are decreasing with time, the furthest crossing in the past (future) has maximum (minimum) elongation. The first crossing after the event is visualised with a red bar, the length marks the percentiles range, and a circle symbol for the median is used. A Mann-Whitney $U$ test with significance level 5 percent for the earthquakes investigated with CSES FGM1 is carried out, flags (yellow stars) at the top of the panels indicate the shift of the medians.

The method is designed to be sensitive to detect magnetic field variations at LEO altitudes which potentially originate from natural hazards. The measured signals in the ionosphere shall carry the imprints of (and close to) lithospheric processes. The conjecture is that the transport of energy and momentum from bottom to top takes place through atmospheric waves.

\section{Results}

The observations indicate that after some energetic lithospheric natural and manmade events, magnetic disturbances at LEO altitudes can possibly be traced back to the source region. In the case studies magnetic field variations from satellite measurements are associated with eligible natural sources, among them earthquakes and volcanic erup- 
tions, and also secondly from artificial factors, in particular rocket launches and strong explosions, see Table 1. The manifold causal relationship via lithospheric atmospheric ionospheric coupling (LAIC) is difficult to establish, but atmospheric acoustic waves (AW) and gravity waves (AGW) can serve as almost line of sight channel to bridge the gap from solid earth to ionospheric heights. This conjecture is supported by theory, observations, and numerical investigations. Measurements indicate main wave activity and dissipation at somewhat lower altitudes, e.g., in case of tsunamis [25], but leaking of energy could lead to pronounced structures and boundary layers at LEO altitudes. If a satellite crosses these structures with sufficient orbital speed the AW or AGW induced pattern in magnetic variation can be considered in first approximation as stationary and sketch out the horizontal dimension along the track.

Table 1. Investigated lithospheric and (near) ground surface events with space based magnetic field measurements from CSES and Swarm satellites at LEO altitudes.

\begin{tabular}{cccc}
\hline No. & Category & Event, Object & Satellite and Instrument \\
\hline 1 & Volcano & Bárðarbunga, Iceland & Swarm A/B/C VFM \\
2 & Earthquake & Severo-Kurilsk, Russia, M6.5 & CSES HPM (FGM1) and Swarm A/B/C VFM \\
3 & & Rio Caribe, Venezuela, M7.3 & CSES HPM (FGM1 and CDSM) \\
4 & & Ndoi Island, Fiji, M8.2 & CSES HPM (FGM1 and CDSM) \\
5 & & Ridgecrest, USA, M7.1 & CSES HPM (FGM1 and CDSM) \\
6 & Explosion & Baumgarten, Austria & Swarm A VFM \\
7 & & Tlahuelilpan, Mexico & CSES HPM (FGM1 and CDSM) \\
8 & Rocket Launch & Falcon 9, SpaceX & Swarm A/B/C VFM \\
9 & & Ariane 5, Arianespace, ESA & Swarm A/B/C VFM \\
\hline
\end{tabular}

\subsection{Volcanoes}

Volcanic explosions and effusions, in particular Plinian eruptions with ejections of ashes into stratospheric heights, have the potential to devastate the surrounding community and local environment, significantly disturb and alter the atmosphere for longer time spans, in specific cases even years, with a marked global temperature decrease and a shift of weather pattern. Here, we consider immediate influences in close temporal proximity to reported and impending volcanic activities and investigate magnetic field variations at LEO altitudes in a spatial box of a few degrees in latitude and longitude around the volcano location. In addition, seismic activity prior to the eruption often relates to such cataclysmic processes. Shults et al. (2016) [26] and Heki et al. (2006) [27] reported ionospheric variations, with regard to volcanoes, based on total electron content (TEC) ground observations, [28] made a survey via measurements of the DEMETER microsatellite, and both $[29,30]$ investigated case studies with the CSES HPM magnetic field package. Such conceptions and considerations can be extended beyond the Earth to the solar system [31].

\section{Bárðarbunga Caldera Collapse and Effusive Eruptions}

Bárðarbunga is one of Iceland's most active subglacial (under the Vatnajökull glacier) basaltic volcanoes. A specific event series-interconnected with magnitude $M>5$ earthquakes and caldera collapse-lasted approximately 6 month, beginning from August 2014 with a seismic swarm to the end of seismic activity in February 2015. The massive lava fissure eruptions in the Holuhraun plain started on 31 August 2014, and were accompanied by huge blasts of $\mathrm{SO}_{2}$ gas [32]. The geodynamic setting consists not only of a volcanic eruption and caldera collapse event, but is associated with high seismicity and caldera earthquakes over a prolonged period, hence a series of complex intertwined sequences. As a case study, Swarm A/B/C satellite magnetic field measurements are used to investigate these processes in a narrow confining spatial range with a box size of only $\pm 1.5 \mathrm{deg}$ in geographical lat/long around Bárðarbunga's location, and an extended time period of \pm 10 days centred around 28 August 2014. This time span is also split in a geomagnetic quiet period up to 26 August 2014 (except 19 August 2014), and, thereafter, a disturbed period 
caused by a geomagnetic storm. All pre-event box crossings are under quiet conditions, i.e., these segments can serve as a low disturbed baseline for post-event crossings. Basically during the magnetic storm phases external influences can have adverse effects, including unwanted spurious signals which interfere with AGW induced variations. The fluctuations of the magnetic field components are studied by wavelet analysis, the corresponding scalograms for one crossing path, together with an illustrative map, are shown in Figure 1. The statistical distributions of the fluctuations for all crossings, i.e., individual pre- and post-event segments, are shown in Figure 2. These are statistics for time slices, similar to the global wavelet spectrum, but with the magnitude of the wavelet transform (nT) instead of the squared values. For Swarm A/C VFM the variations in the X-and Y-component (horizontal plane) after the event are increased (higher red bar), the Z-component is nearly constant. In the Swarm B VFM measurements only the Y-component is found to increase after the event.
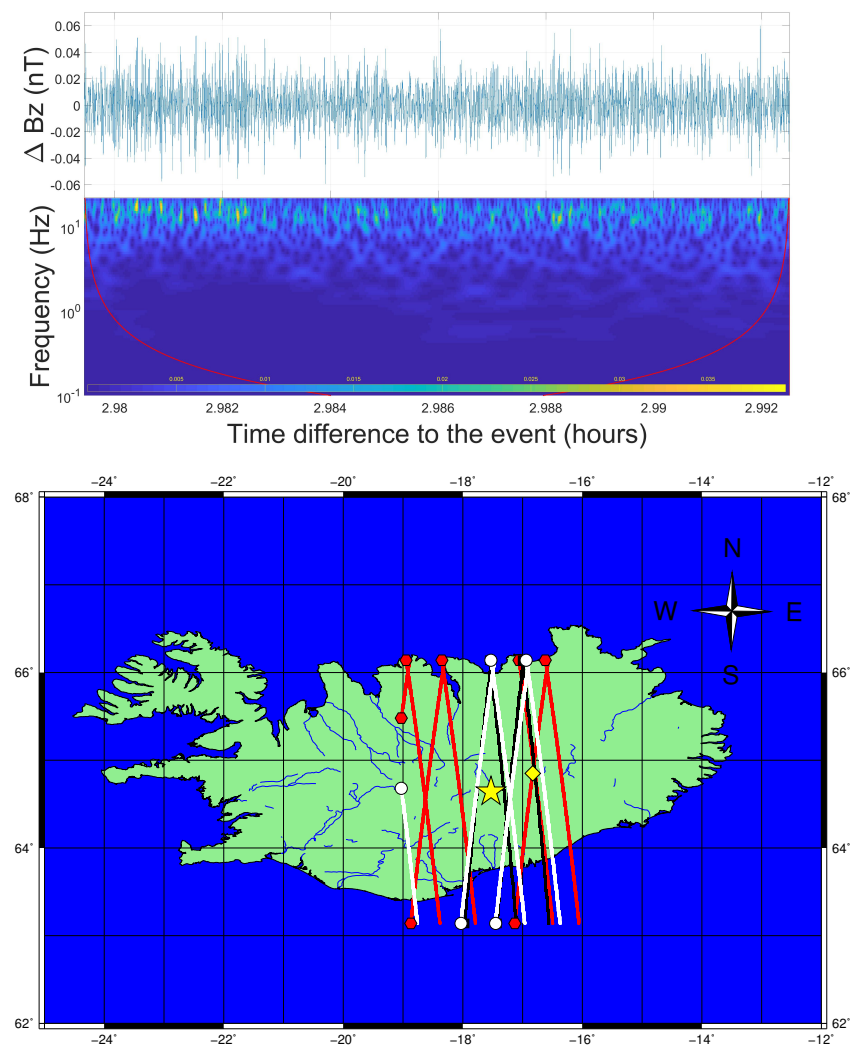

(b)

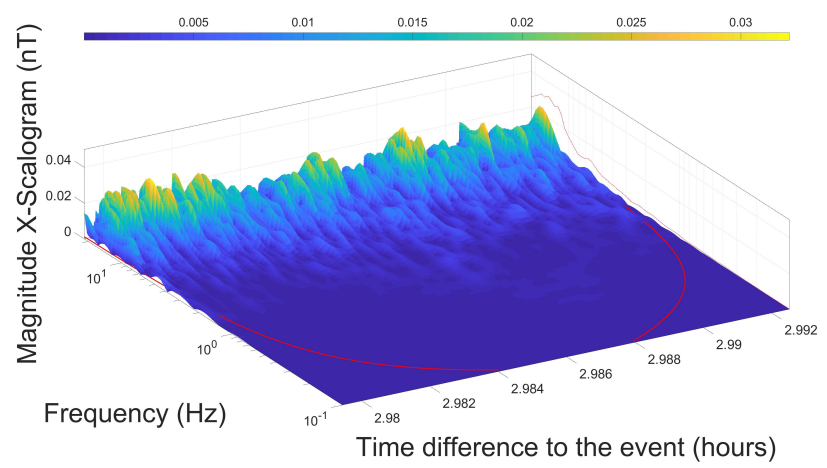

Figure 1. Cont. 


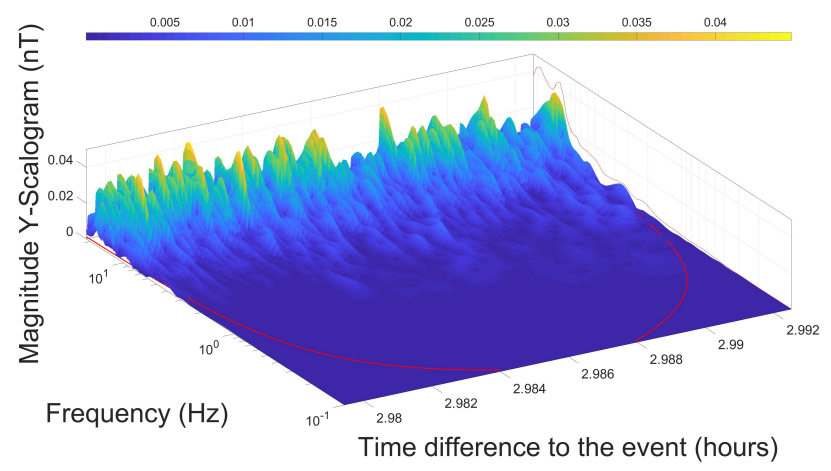

(d)

Figure 1. (a): Magnetic field variation $\Delta B_{z}(\mathrm{nT})$ time series from Swarm A VFM ( $\left.50 \mathrm{~Hz}\right)$ and scalogram for a post-crossing with a time lag of $+3 \mathrm{~h}$ of the 28 August 2014 volcanic eruption event (Holuhraun 1), Bárðarbunga, Iceland. The so-called "cone of influence" (red line in the spectra) divides the wavelet spectrum in two parts, in the inner (large) area edge effects according to the chosen parameters are negligible. (b): Coarse map of Iceland with the illustration of the Bárðarbunga volcano (yellow star), the Holuhraun lava field (yellow diamond), and the footprints of Swarm A (7 traces, red colour), Swarm B (4 traces, black), and Swarm C (5 traces, white) for the investigated eruption time span 28 August $2014 \pm 10$ days within the spatial domain given in a box size (footprint area) of $\pm 1.5 \mathrm{deg}$ in latitude and longitude centred around Bárðarbunga. The ingress points are marked with larger symbols, i.e., north-south crossings or vice versa are readily identifiable. (c): Oblique view of a Swarm A VFM single trace scalogram based on $\Delta B_{x}$ (nT) time series variations with noticeable fluctuations (after wavelet analysis) in the higher frequency range (smaller scales), i.e., attenuations and enhancements of magnetic field fluctuations possibly given by AGW interaction with the F-region plasma. (d): like in (c), 3D scalogram view for the $\Delta B_{y}(\mathrm{nT})$ component.

Swarm A VFM variations, Bárðarbunga volcano, Iceland // box \pm 1.5 deg, date 2014-08-28, time span \pm 10 days

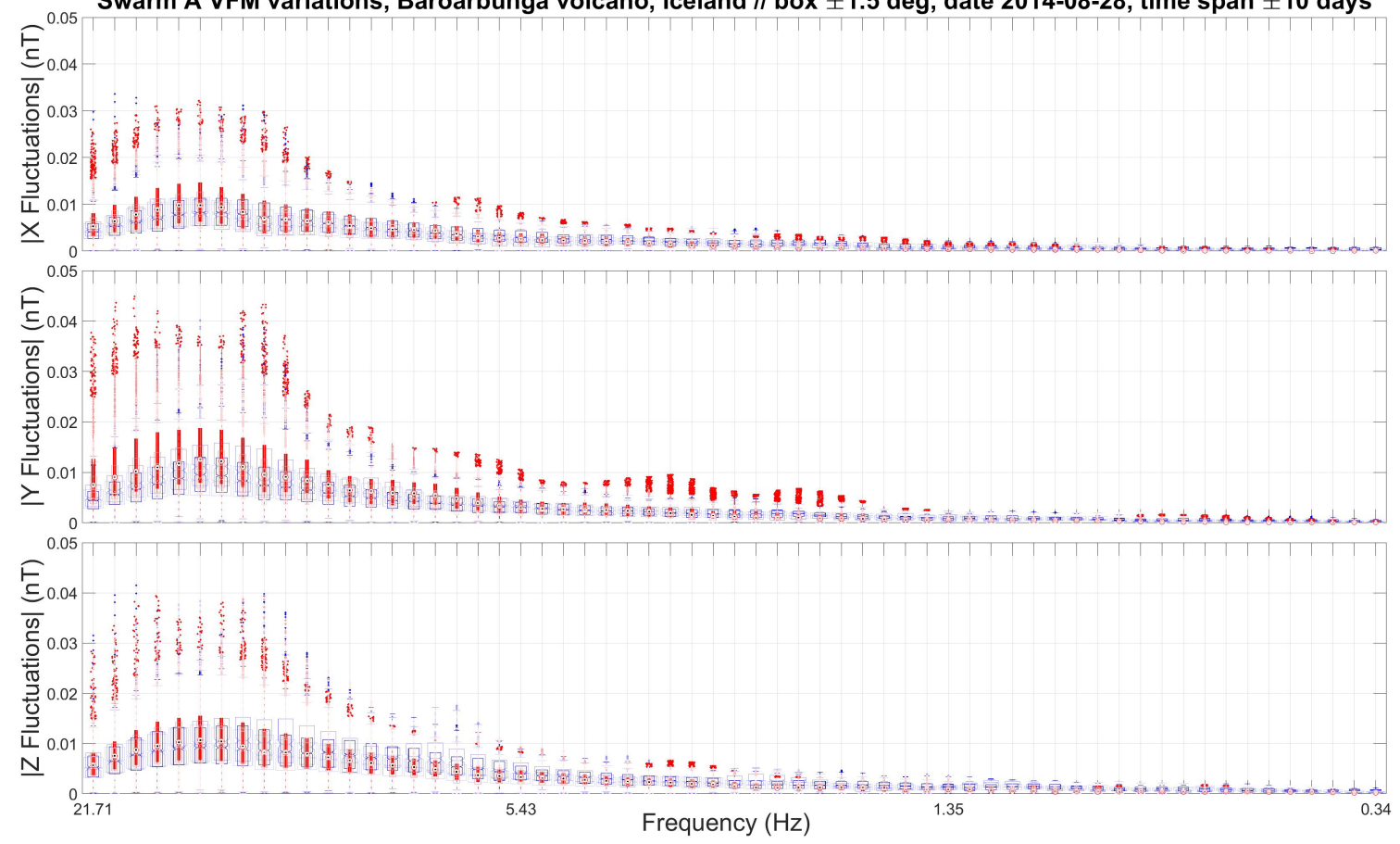

Figure 2. Cont. 

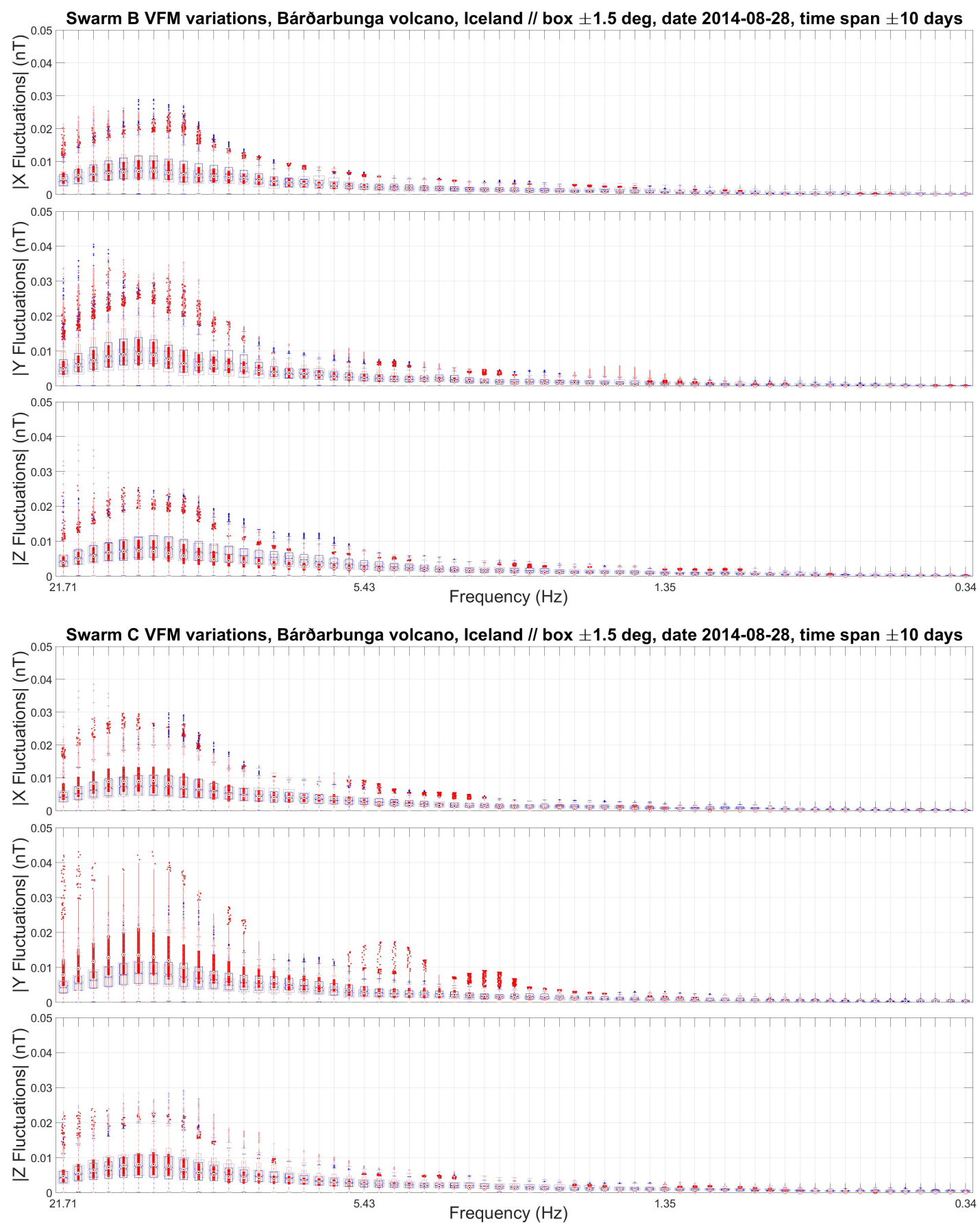

Figure 2. Distribution of Swarm A/B/C (top/centre/bottom panel) VFM magnetic field fluctuations (box plots) after wavelet transform grouped in individual frequency bands for the August 2014 volcanic event, Bárðarbunga, Iceland. The numbers of pre- or post-crossings for Swarm A/B/C are $\{3-4 / 2-2 / 2-3\}$. The colour coding \{pre/post $\}$ is $\{$ blue/red $\}$ with gradually desaturation $\{$ blueish/reddish\} for larger $\Delta \mathrm{t}$ (interval between crossing and event).

\subsection{Earthquakes}

Seismic phenomena are a rich area of research and ubiquitous at substantial scales throughout the terrestrial body, in particular together with the propagation and coupling of seismic waves with the environment. We investigate four large earthquakes with moment magnitudes $M \geq 6.5$ accessible with CSES and Swarm magnetic field data in a time period a few days around the event in order to get pre- and post-background behaviour and at best foreshock signatures, see Table 2. For common investigations and statistical analysis, 
according to the United States Geological Survey (USGS) database, 59 earthquakes occurred in the period 1 March 2018 to 31 July 2019.

Table 2. Investigated earthquakes with space based magnetic field measurements by LEO satellites.

\begin{tabular}{|c|c|c|c|c|c|c|}
\hline No. & USGS ID & Event & Date & Mag & Depth & Satellite and Instrument \\
\hline 1 & us1000hacw & Severo-Kurilsk, RUS & 2018-10-10 & M6.5 & 20 km & CSES FGM1, Swarm VFMs \\
\hline 2 & us1000gez7 & Rio Caribe, VEN & 2018-08-21 & M7.3 & $146.8 \mathrm{~km}$ & CSES HPM (FGM1 and CDSM) \\
\hline 3 & us1000gcii & Ndoi Island, FJI & 2018-08-19 & M8.2 & 600 km & CSES HPM (FGM1 and CDSM) \\
\hline 4 & ci38457511 & Ridgecrest, USA & 2019-07-06 & M7.1 & $8 \mathrm{~km}$ & CSES HPM (FGM1 and CDSM) \\
\hline
\end{tabular}

\subsubsection{Earthquake M6.5 Severo-Kurilsk, Russia}

The so-called Pacific Ring of Fire, with its subduction zones, is a hotspot of volcanic and earthquake activity. Here we focus on the M6.5 earthquake near Severo-Kurilsk, Kuril Islands, Russia, where the data enables common CSES and Swarm investigations, see Figure 3. This provides a testbed at the Kuril-Kamchatka trench to compare high magnitude events at different times and hypocenters. CSES FGM1 shows an increase in fluctuations for all three components, i.e., the variations are higher after the earthquake occurrence. Swarm B had only one post-crossing. Swarm A VFM shows higher variations than Swarm C VFM, the three components have varying maxima in different frequency bands (wavelike transition between frequencies and scales).

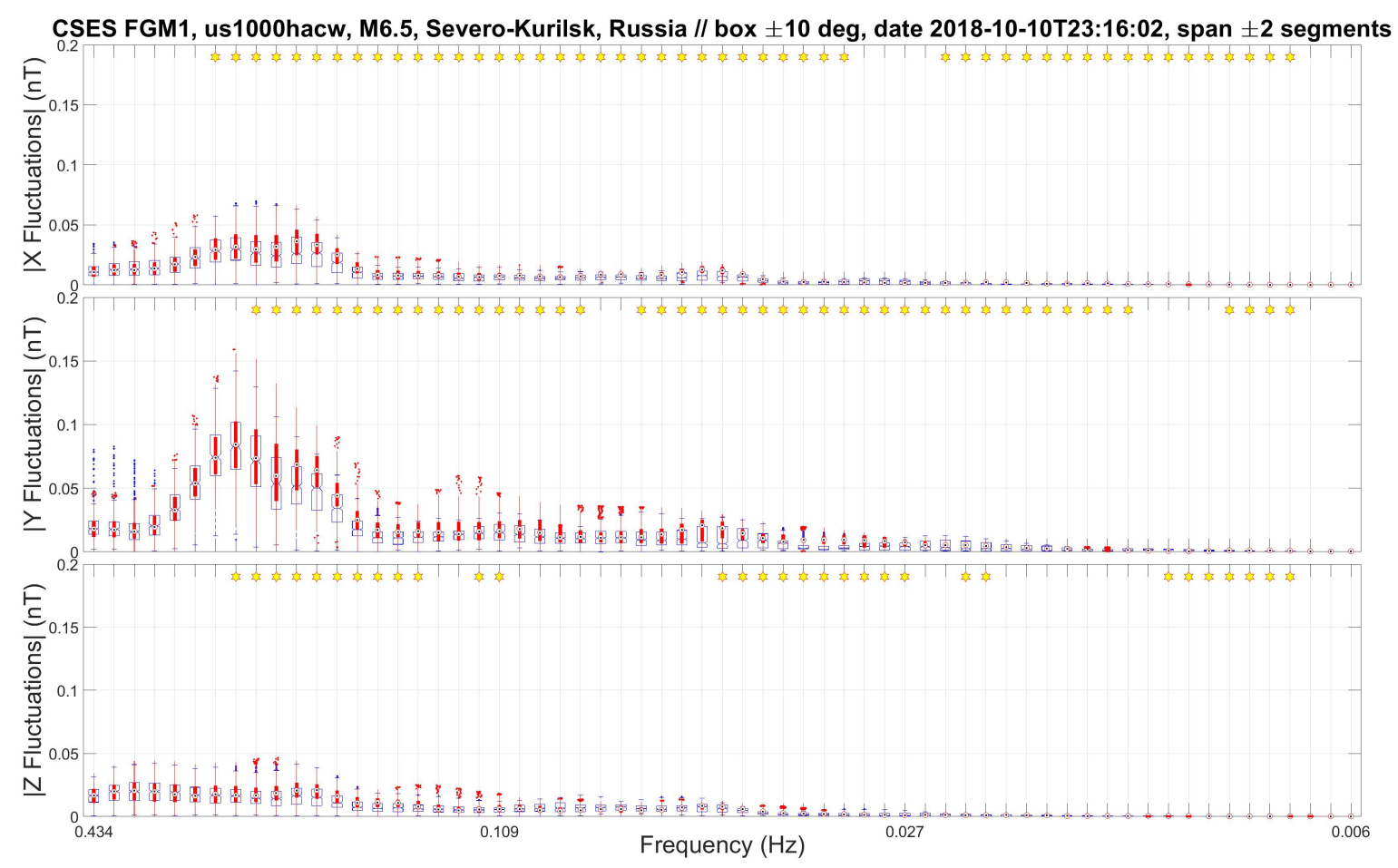

Figure 3. Cont. 


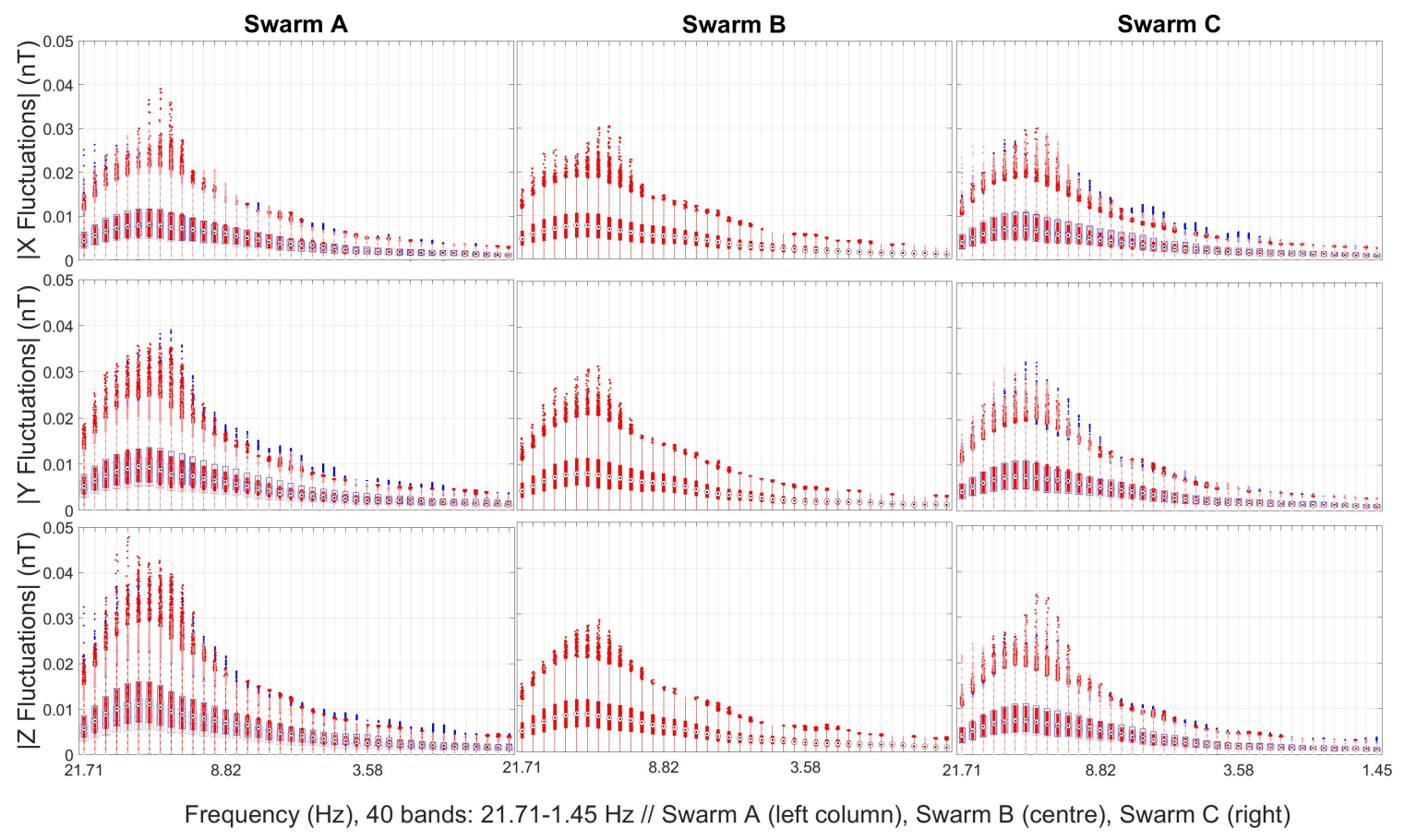

Figure 3. Combined CSES and Swarm investigation of the earthquake M6.5 (focal depth $20 \mathrm{~km}$ ), Severo-Kurilsk, Russia, the box size is in both cases \pm 10 degrees. Top: Distribution of CSES FGM1 magnetic field fluctuations for the $X-$, Y-, and Z-components grouped in individual frequency bands. The time span is \pm 2 segments, i.e., in this case $\Delta t=\{-1.36$, $-0.37,-0.31,0.67,2.65\}$ days shift to the EQ at 2018-10-10T23:16:02. Bottom: Distribution of Swarm A/B/C VFM magnetic field fluctuations after wavelet analysis. The relative timing for the segments are $t_{A}=\{-1.96,-1.46,0.54,1.01\}$ days, $t_{B}=$ $\{0.85\}$ days (only one post crossing), and $t_{C}=\{-1.97,-1.46,0.54,1.01\}$ days. The colour coding is the same as in Figure 2, i.e., $\{$ pre/post $\}$ is $\{$ blue/red $\}$ with gradually desaturation (fading) for larger $\Delta t$ (interval between crossing and event). Geomagnetic activity, derived from the Disturbance Storm Time (Dst) index, is $\mid$ Dst $\mid \leq 41 \mathrm{nT}$ for the whole period.

\subsubsection{Earthquake M7.3 Rio Caribe, Venezuela}

The investigation is performed using CSES HPM (FGM1 and CDSM) and the data availability is from July 2018 to July 2019. In this period, USGS reported 21 earthquakes with magnitude $M \geq 7$ and a wide spread in focal depth, ranging from shallow, e.g., $8 \mathrm{~km}$ in the case of the Ridgecrest earthquake sequence, up to deep seated earthquakes with a focal depth of $670.8 \mathrm{~km}$ in the case of Suva, Fiji. The Rio Caribe, Venezuela, EQ (USGS ID us1000gez7) had magnitude M7.3 with a focal depth of $146.8 \mathrm{~km}$, the distribution of the magnetic field fluctuations are shown in Figure 4. CDSM shows wavelike features in the frequency bands, i.e., enhancement and attenuation in varying order. For FGM1 the fluctuations in the Y-component are larger than in the X-and Z-components, but for all three components the fluctuations over the whole frequency range are higher after the earthquake. 

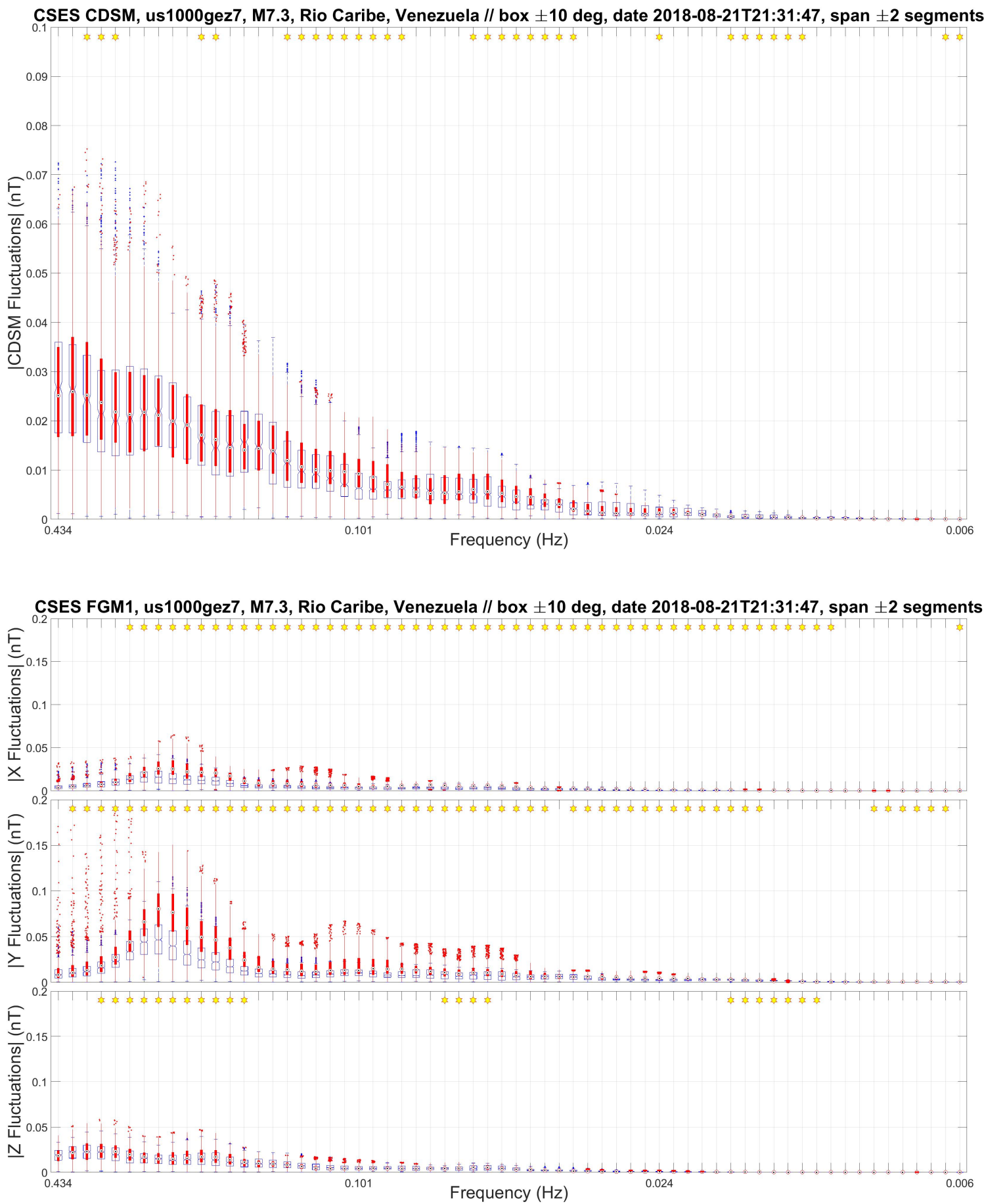

Figure 4. CSES investigation of the earthquake USGS event us1000gez7 with magnitude M7.3, Rio Caribe, Venezuela, focal depth $146.8 \mathrm{~km}$, with a spatial dimension (box size) of \pm 10 degrees. Top: Distribution of CSES CDSM magnetic field fluctuations grouped in individual frequency bands. The step size is in log-scale according to $\ln \left(f_{n}\right)=-0.7651-0.069315 \times$ $\mathrm{n}$, shown is the range $\mathrm{n}=\{1-64\}$, i.e., the left box plot $(\mathrm{n}=1)$ is $\mathrm{f}_{1}=0.4341 \mathrm{~Hz}$ (Nyquist frequency $f_{s} / 2=1 / 2 \mathrm{~Hz}$ ) and the right box plot $(n=64)$ is $f_{64}=0.0055 \mathrm{~Hz}$. Only satellite orbits during night times are considered. The time span around the EQ is \pm 2 segments, i.e., in this case $\Delta t=\{-2.61,-1.62,-0.64,0.34,1.33\}$ days shift to the EQ at 2018-08-21T21:31:47. Bottom: Distribution of the CSES FGM1 magnetic field fluctuations after scalogram processing. The colour coding is the same as in Figure 2, the geomagnetic activity is $|\mathrm{Dst}| \leq 20 \mathrm{nT}$ for the selected time span. 


\subsubsection{Earthquake M8.2 Ndoi Island, Fiji}

The Ndoi Island, Fiji, EQ (USGS ID us1000gcii) had a magnitude M8.2 with a focal depth of $600 \mathrm{~km}$, the distribution of the magnetic field fluctuations are shown in Figure 5 . CDSM shows a wavelike behaviour along the frequency bands, the upper bands (lower frequencies) are dominated by the pre-earthquake crossings (higher blue bars according to the colour coding). The fluctuations for FGM1 are generally low, the X-and Z-components along the frequency bands are attenuated after the earthquake.
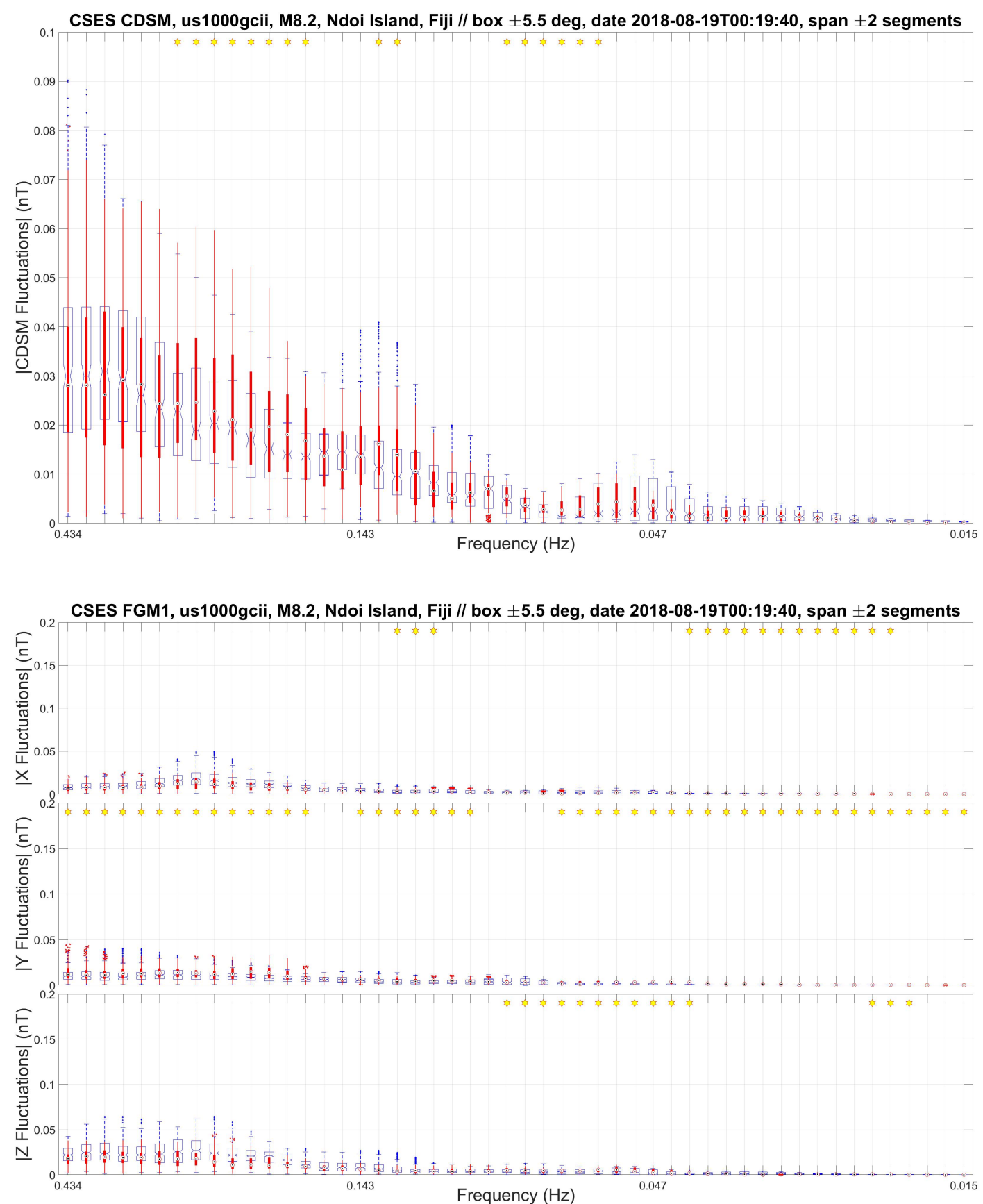

Figure 5. CSES investigation of the earthquake USGS event us1000gcii with magnitude M8.2, Ndoi Island, Fiji, focal depth $600 \mathrm{~km}$, with a spatial dimension (box size) of \pm 5.5 degrees, but only crossings during night times and east of the event site are considered. Top: Distribution of CSES CDSM magnetic field fluctuations grouped in individual frequency bands. The time span around the EQ is \pm 2 segments, i.e., in this case $\Delta t=\{-6.44,-2.43,-1.44,2.57,3.55\}$ days shift to the EQ at 2018-08-19T00:19:40. Bottom: Distribution of the CSES FGM1 magnetic field fluctuations after wavelet analysis. The colour coding is the same as in Figure 2, geomagnetic activity is $\mid$ Dst $\mid \leq 37 \mathrm{nT}$ for the selected time span. 


\subsubsection{Earthquake M7.1 Ridgecrest, USA}

The Ridgecrest, USA, EQ (USGS ID ci38457511) had a magnitude M7.1 with a focal depth of $8 \mathrm{~km}$ and is the largest one from the corresponding seismic sequence. The distribution of the magnetic field fluctuations are shown in Figure 6. CDSM shows a wavelike behaviour, FGM1 a sinusoidal modulation along the bands.
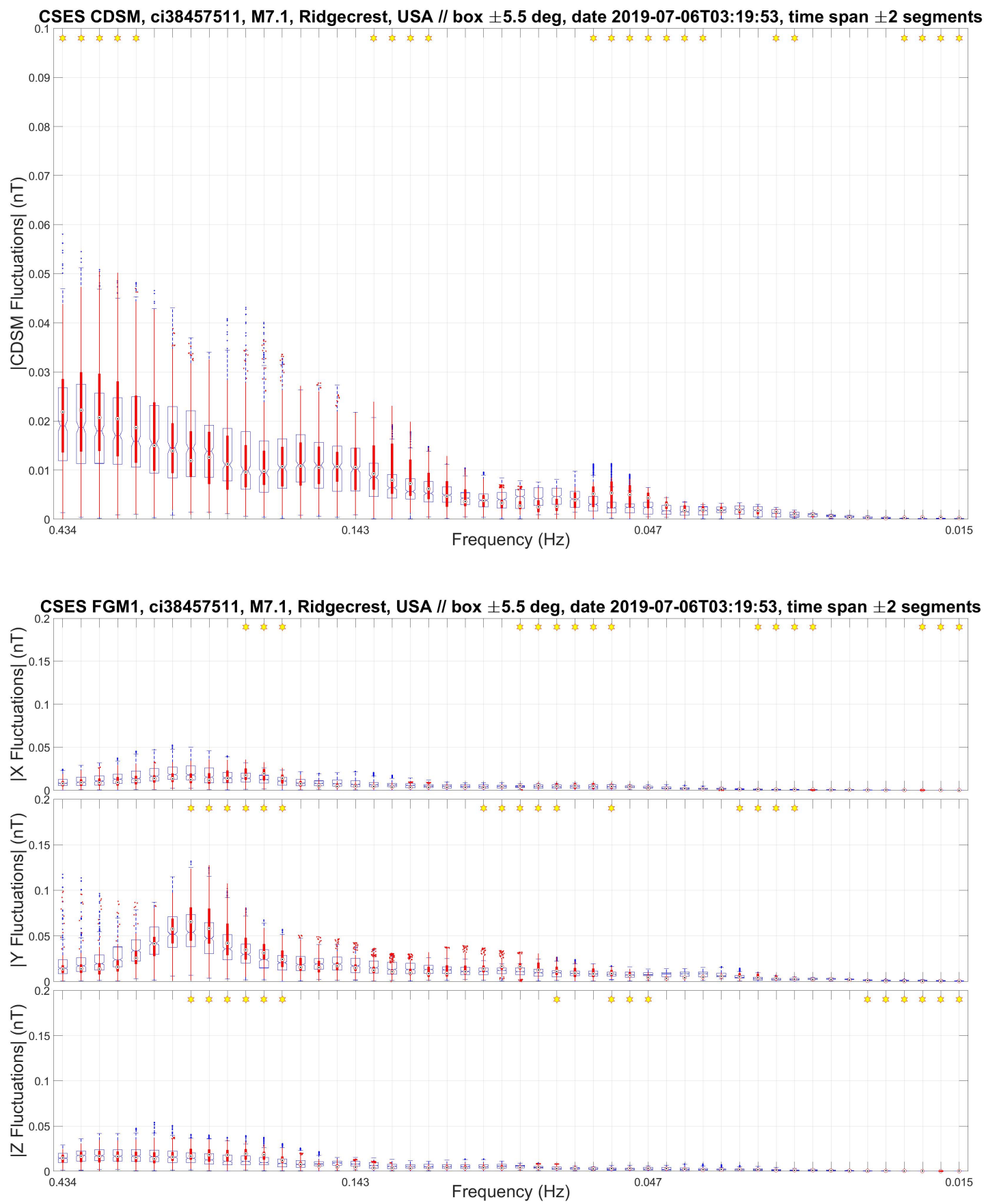

Figure 6. CSES investigation of the earthquake USGS event ci38457511 with magnitude M7.1, Ridgecrest, USA, focal depth $8 \mathrm{~km}$, with a spatial dimension (box size) of \pm 5.5 degrees, only crossings during night times are considered. Top: Distribution of CSES CDSM magnetic field fluctuations grouped in individual frequency bands. CDSM is found to display a wavelike behaviour. The time span around the EQ is \pm 2 segments, i.e., in this case $\Delta t=\{-4.73,-3.75,-2.76,0.27,1.25\}$ days shift to the EQ at 2019-07-06T03:19:53. Bottom: Distribution of the CSES FGM1 magnetic field fluctuations after wavelet analysis. The colour coding is the same as in Figure 2, geomagnetic activity is $|\mathrm{Dst}| \leq 17 \mathrm{nT}$ for the selected time span. 


\subsection{Explosions}

Among several natural and artificial phenomena, not only natural hazards could be responsible for acoustic waves and atmospheric gravity waves. Strong explosions and blasts, i.e., impulsive point sources, have a similar effect like powerful volcanic eruptions with an instantaneous energy release and could, therefore, generate gravity and acoustic waves too. In the recent past the devastating explosion from Beirut, Lebanon, on 4 August 2020, was detected with ionospheric total electron content (TEC) measurements from ground based Global Navigation Satellite System (GNSS) receivers [33].

\subsubsection{Baumgarten Natural Gas Hub Technical Failure}

A dangerous incident in Central Europe was a sudden gas release together with a serious fire in Baumgarten, Austria. On 12 December 2017, a technical failure in the natural gas hub effectively resulted in an explosion, which could be detected with a seismic array [34]. In order to investigate this precisely timed accident from LEO altitudes the box size has to be at least $\pm 3.5 \mathrm{deg}$ in lat/long to have a minimum of two satellites in the time span \pm 1 day around the event. There are small magnetic field variations in the traces, see Figure 7 (shown for Swarm A VFM after wavelet analysis), in particular an enhancement in the Y-component, but the time- and distance-gap between the satellite traces and the location is too large to assign these features to this event.

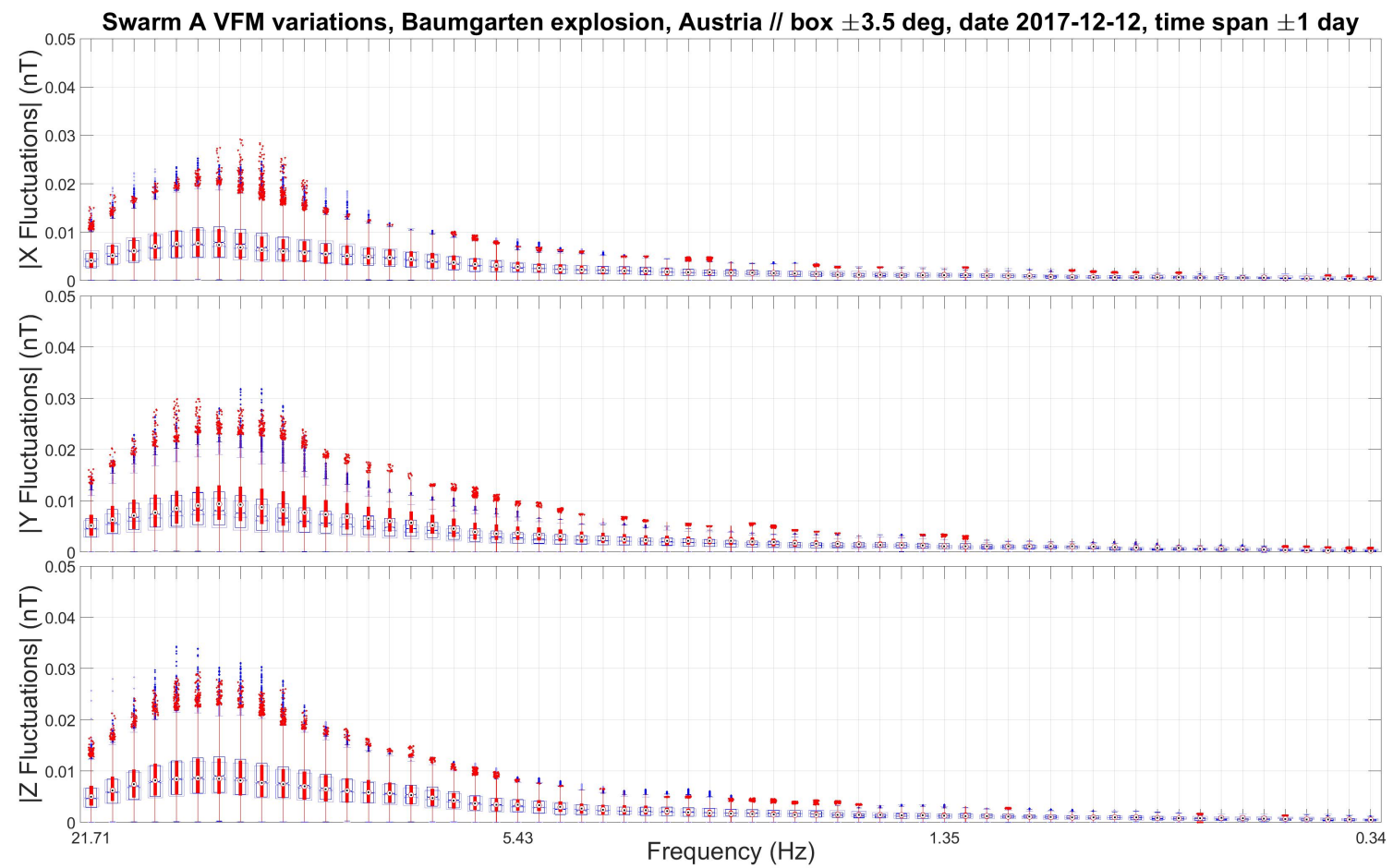

Figure 7. Distribution of Swarm A VFM magnetic field fluctuations grouped in individual frequency bands for the explosion (2017-12-12T07:45 UTC) in Baumgarten, Austria. The colour coding is the same as in Figure 2, the geomagnetic activity is $\mid$ Dst $\mid \leq 29 \mathrm{nT}$ for the selected time span.

\subsubsection{Tlahuelilpan Pipeline Explosion}

Another man-made catastrophe was the gasoline pipeline explosion in the town of Tlahuelilpan in the Mexican state of Hidalgo on 18 January 2019. According to eyewitness reports a fuel spill ignited into a fireball with tragically loss of life for many people in the immediate vicinity. Such a shock wave at the ground has the ability to release energy into far distance. For CSES HPM the variations are shown in Figure 8. For most of the frequency bands CDSM has an enhancement, i.e., higher values after the explosion. The pre- and postvariations for FGM1 are similar, the Y-component values are larger, all three components 
have a slightly wavelike feature (redistribution between scales) along their particular frequency band axis.
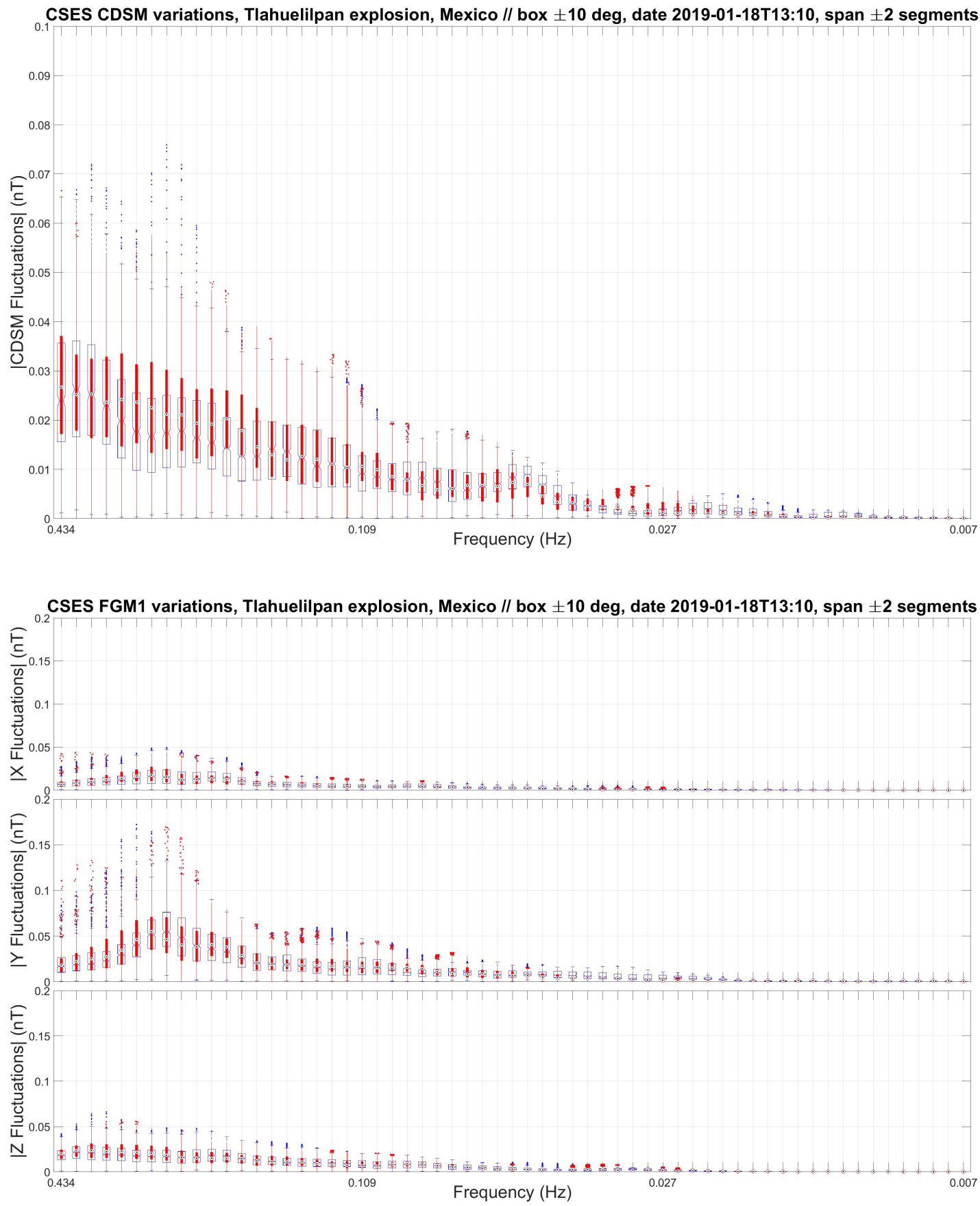

Figure 8. Distribution of CSES CDSM (top) and FGM1 (bottom) magnetic field fluctuations grouped in individual frequency bands for the Tlahuelilpan, Mexico, event, 2019-01-18T13:10 UTC. The time shift to the event is $\Delta t=\{-1.21,-0.66,-0.22$, $0.33,0.83\}$ days. The colour coding is the same as in Figure 2, the geomagnetic activity is $\mid$ Dst $\mid \leq 15 \mathrm{nT}$ for the selected time span.

\subsection{Rocket Launches}

Acoustic shock waves, which are basically similar to processes in explosions, have the peculiarity to initiate ionospheric disturbances. Striking examples are rocket launches with wave generation in the exhaust wake during supersonic ascents, measurements and results are inter alia from ionospheric sounders and Global Positioning System (GPS) receiver 
networks [35]. In two case studies we investigate if the disturbances are detectable with magnetic field measurements at LEO altitudes.

\subsubsection{Falcon 9 Launch}

The statistical evaluation of Swarm A/B/C VFM magnetic field fluctuations for the SpaceX Falcon 9 launch on 2020-11-21T17:17:08 UTC (payload Sentinel-6 Michael Freilich satellite) from Vandenberg Air Force Base, California, USA, is shown in Figure 9. In general the components are similar, but a distinct attenuation of fluctuations over the entire frequency band is observed in the Y-component of Swarm C VFM, the Y-and Z-components of Swarm B VFM are clearly enhanced. In this particular event with the given parameters (box size lat/long $\pm 5.5 \mathrm{deg}$, time span \pm 1 day) there are four crossings for each Swarm satellite. On the basis of the orbit constellation Swarm A/C are close in the temporal and spatial domains, which basically enables an intended dual satellite investigation. However, for this event the two post crossings have time gaps of $\Delta t=\{+1.15\}$ days, i.e., ionospheric disturbances triggered by the rocket launch are presumably dissipated, magnetic field fluctuations cannot be linked to the launch. Swarm B has one crossing before and three crossings after the SpaceX Falcon 9 lift-off, $\Delta t=\{-0.40,+0.11,+0.59,+1.10\}$ days, the measurements show distinct enhancements in the fluctuations for the first crossing after the launch. We contend that this magnetic field variation can be linked to ionospheric structures caused by atmospheric waves generated along the first part of the launch vehicle ascent trajectory.

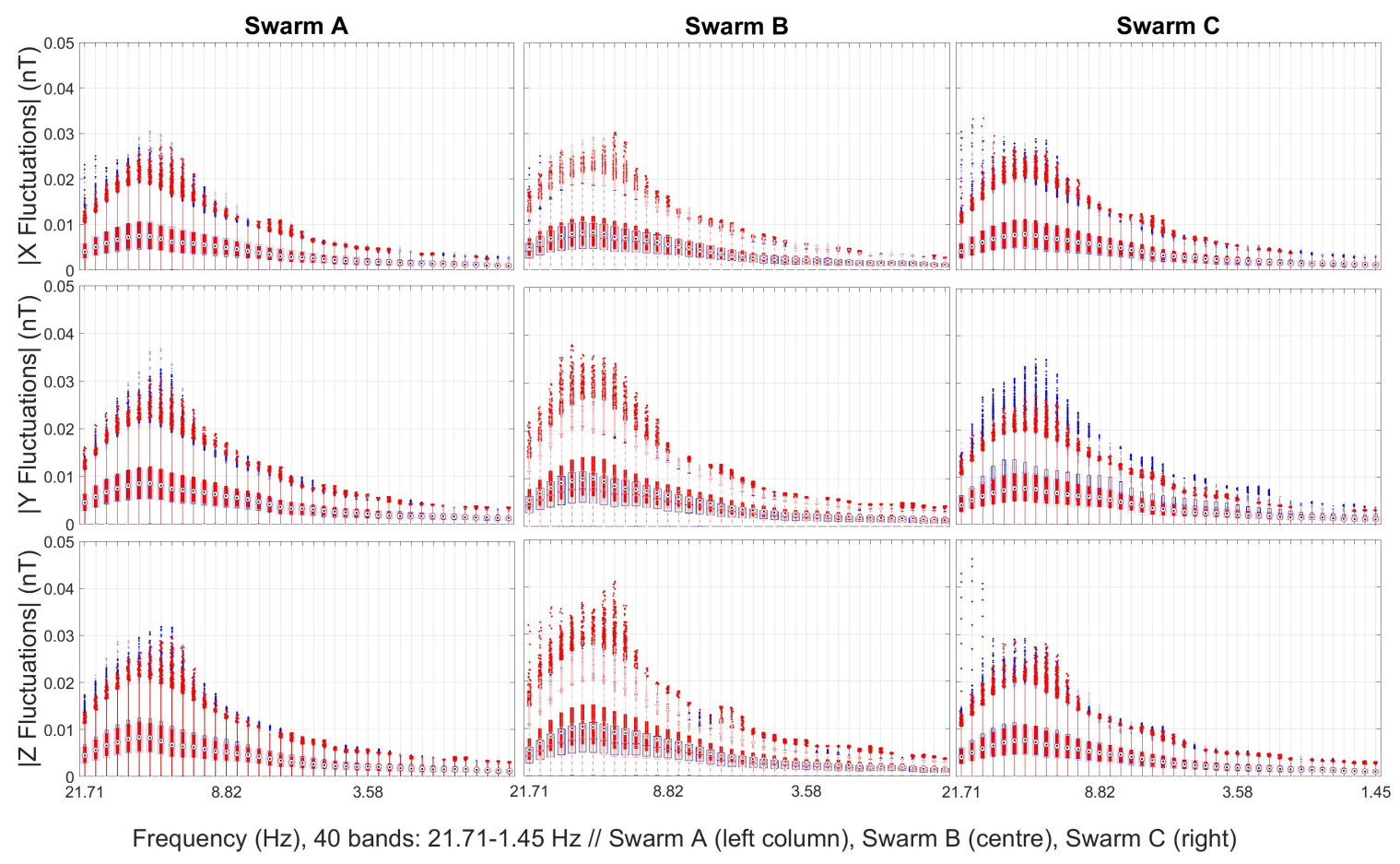

Figure 9. Distribution of Swarm A/B/C VFM magnetic field fluctuations after wavelet analysis grouped in individual frequency bands for the SpaceX Falcon 9 launch, Vandenberg Air Force Base, California, USA. The spatial box size is $\pm 5.5 \mathrm{deg}$, date 21 November 2020 (payload Sentinel-6 Michael Freilich satellite), and time span \pm 1 day. For Swarm B VFM (middle column) the individual crossing segments relative to the take off moment are $\Delta t=\{-0.40,+0.11,+0.59,+1.10\}$ days All three components for the first crossing after the launch $(\Delta t=\{+0.11\}$ days) are enhanced (bars in red colour). The colour coding is the same as in Figure 2, the geomagnetic activity is $\mid$ Dst $\mid \leq 38 \mathrm{nT}$ for the selected time span.

\subsubsection{Ariane 5 Launch}

On 25 July 2018, an Ariane 5 ES rocket was successfully launched into orbit from the Guiana Space Centre, near Kourou, French Guiana, aboard with four navigation satellites 
from Galileo GNSS. We investigate this rocket ascent (VA-244, and further launches) from this site near the equator with tropical climate, because the defined sequences repeatedly occur and, therefore, enable the possibility of launch event comparisons several times per year. The fluctuation statistics for a Swarm A/B/C VFM scalogram investigation is shown in Figure 10. Swarm A VFM has an attenuation in the Y- and Z-components, Swarm B/C VFM measurements are similar in all components.

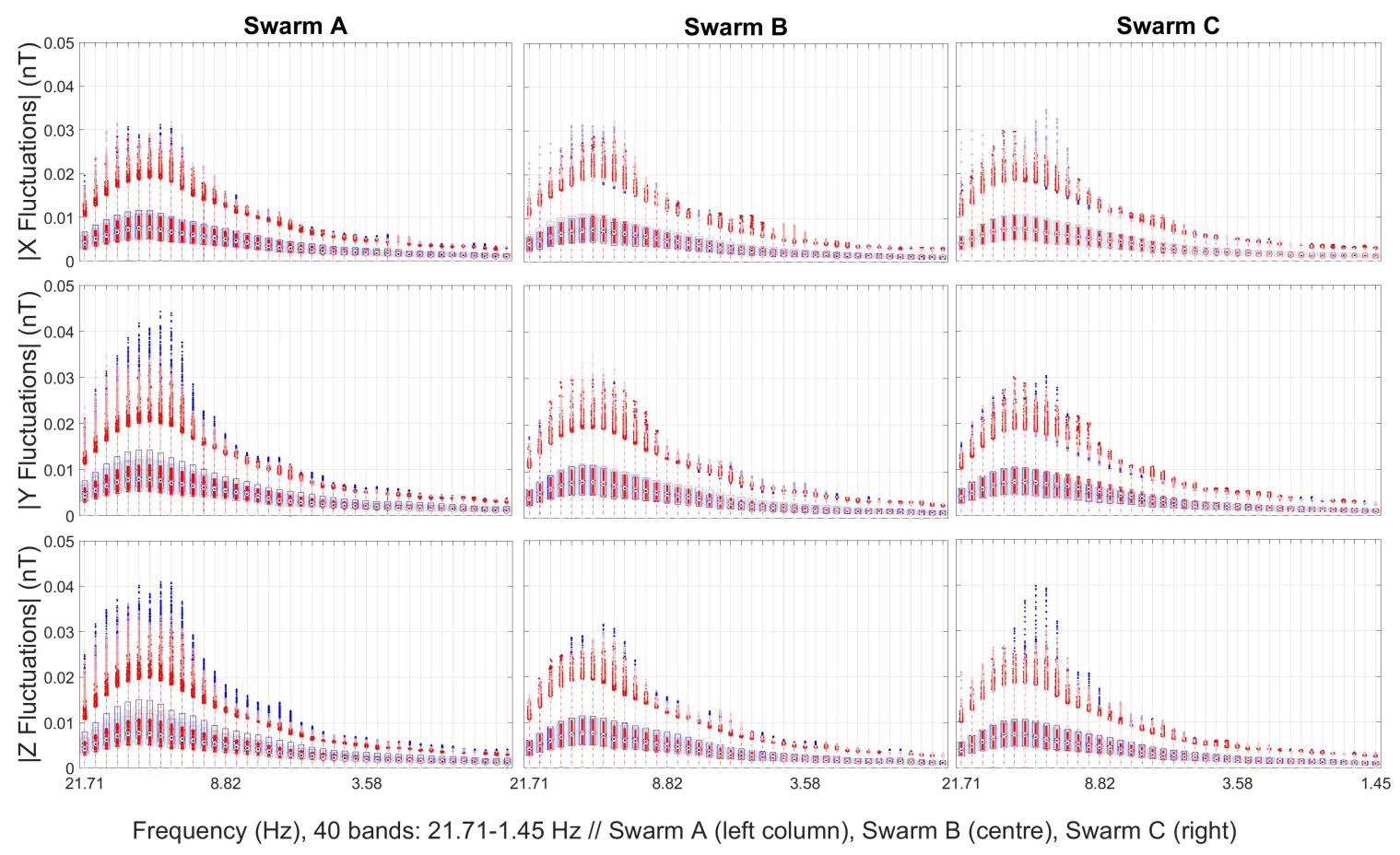

Figure 10. Distribution of Swarm A/B/C VFM magnetic field fluctuations after scalogram processing and grouped in individual frequency bands for an Ariane 5 launch, 25 July 2018, box size $\pm 10 \mathrm{deg}$, time span \pm 1 day. The frequency band is in log-scale according to $\ln \left(f_{n}\right)=3.1469-0.069315 \times n$, shown is the range $n=\{1-40\}$, i.e., the left box plot ( $\left.n=1\right)$ is $\mathrm{f}_{1}=21.7062 \mathrm{~Hz}$ (Nyquist frequency $f_{s} / 2=25 \mathrm{~Hz}$ ) and the right box plot $(\mathrm{n}=40)$ is $\mathrm{f}_{40}=1.4540 \mathrm{~Hz}$. The colour coding is the same as in Figure 2, the geomagnetic activity is $|\mathrm{Dst}| \leq 174 \mathrm{nT}$ (start and main phase of a magnetic storm) for the selected time span.

\section{Discussion}

By applying novel satellite magnetic field techniques and approaches on existing state-of-the-art best practises it is possible to circumspectly answer some of the most prominent questions in natural hazards investigations. Magnetic field variations in the ionosphere can shed light on processes in the lithosphere, Earth's surface and above ground. In any configuration the orbital recurrence intervals are crucial points in order to get many crossing segments in the survey area of few degrees around a target. A constellation of satellites like ESA's Swarm mission has inherently advantages, the CSES-2 expansion, together with CSES, will double the revisiting frequency and is very encouraging. The highres $50 \mathrm{~Hz}$ sampling enables statistical analyses of each individual segment, either before or after an event. A $1 \mathrm{~Hz}$ temporal resolution, due to limited number of vectors per single crossing within a selected investigation area (box size), induces a merging of pre- and post-event periods (which could slightly differ), i.e., only two time spans are effectively available for the evaluation. An analysis to remove confounding effects is obligatory, among them spacecraft interferences and external sources like magnetospheric (mainly in high latitudes) and solar influences on the ionospheric F-region plasma. In that sense the practical experience of instrument teams and amassed evidence through real-time services in the field of near Earth space can provide important knowledge to detect spurious signals. Future research directions include a thorough characterisation of the AW- and 
AGW-channel into the upper atmosphere and the coupling mechanisms between neutral particles and the ambient plasma population. By combining a variety of multi-parameter methods to describe the phenomena more details will show up. An outlook is to transform these results with an all-encompassing perspective into an essential space based service to leverage natural hazards evaluation and risk assessment.

\section{Materials}

The ESA Swarm mission data access and data policy is publicly available via the web page earth.esa.int/web / guest/swarm/data-access (accessed on 19 March 2021), L1b-data are used, in particular the magnetic field high-res $50 \mathrm{~Hz}$ files with their meta-data (stored in a single file per day per satellite A/B/C) under the "latest baseline folder". The CSES data access and data policy is by the link www.leos.ac.cn (accessed on 19 March 2021), a registration and completion of a request form is necessary, HPM L2-data in Hierarchical Data Format version 5 (HDF5) are mainly used; a second source are data (calibrated according the nominal standards, i.e., L2 pipeline) from intercalibration campaigns of the CSES HPM instrument suite (checked for spurious satellite disturbances). In both cases ordinary (ftp-)clients and unzip-software are sufficient to get the requested data products. The Swarm datasets are in the Common Data Format (CDF), ordinary software is used to read the data. The earthquake catalogue is from the United States Geological Survey (USGS) via the application programming interface earthquake.usgs.gov (accessed on 15 March 2021), a script handles the on-demand access (query string and result form). Information and activity status about volcanos are from VolcanoDiscovery web.volcanodiscovery.com (accessed on 22 March 2021) and from the Global Volcanism Program of the Smithsonian Institution volcano.si.edu (accessed on 22 March 2021). In both cases textual parts and descriptions are manually translated into machine readable sequences (mainly about eruption type and timing aspects). The events presented in this paper were checked with respect to geomagnetic disturbances. The calculated geomagnetic indices were made available by International Service of Geomagnetic Indices (ISGI) isgi.unistra.fr (accessed on 29 March 2021) collaborating institutes from data collected at magnetic observatories. The map is generated with the software GMT 5 [36]. Programmes (scripts and functions) are written with the software Matlab (version R2019a; "The MathWorks, Inc.; Natick, MA, USA") under Windows 10 ("Microsoft Corporation, Redmond, USA") operating system.

\section{Conclusions}

In most of the presented cases and events the statistical results from the wavelet analysis show a change in the pattern between pre- and post-event periods. Wavelike features are found for the China Seismo-Electromagnetic Satellite (CSES) Coupled Dark State Magnetometer (CDSM) scalar measurements. The analysis of the components from the vector field instruments, i.e., CSES fluxgate magnetometer (FGM1) and Swarm A/B/C Vector Field Magnetometer (VFM), show enhancements and attenuations along specific frequency bands. The spatio-temporal confinement to a few degrees in lat/long directs the focus to a limited area, which could be a part (diameter) of a complex atmospheric wave propagation channel from bottom to top, in a certain sense a cross section from a transmission tube which is traversed by satellites at Low Earth Orbit (LEO) altitudes. The synchronous behaviour of the Swarm A/C VFM components for the Bárðarbunga (Iceland) volcano sequence suggests a transit through the same structure, observational biases in causing this trend are unlikely. Enhancements, mainly for the earthquake events, see Figure 11 for CSES FGM1 case studies, indicate energy transfer to the plasma, the wavelike feature a redistribution between different scales and later on dissipation occurs to background levels. The small enhancements from the explosion events could be related to compressional signatures from acoustic waves, but overall the pattern are weak. For the rocket launches at least one component shows alterations, energy transfer into the plasma at LEO altitudes related to acoustic waves is a reasonable explanation. 


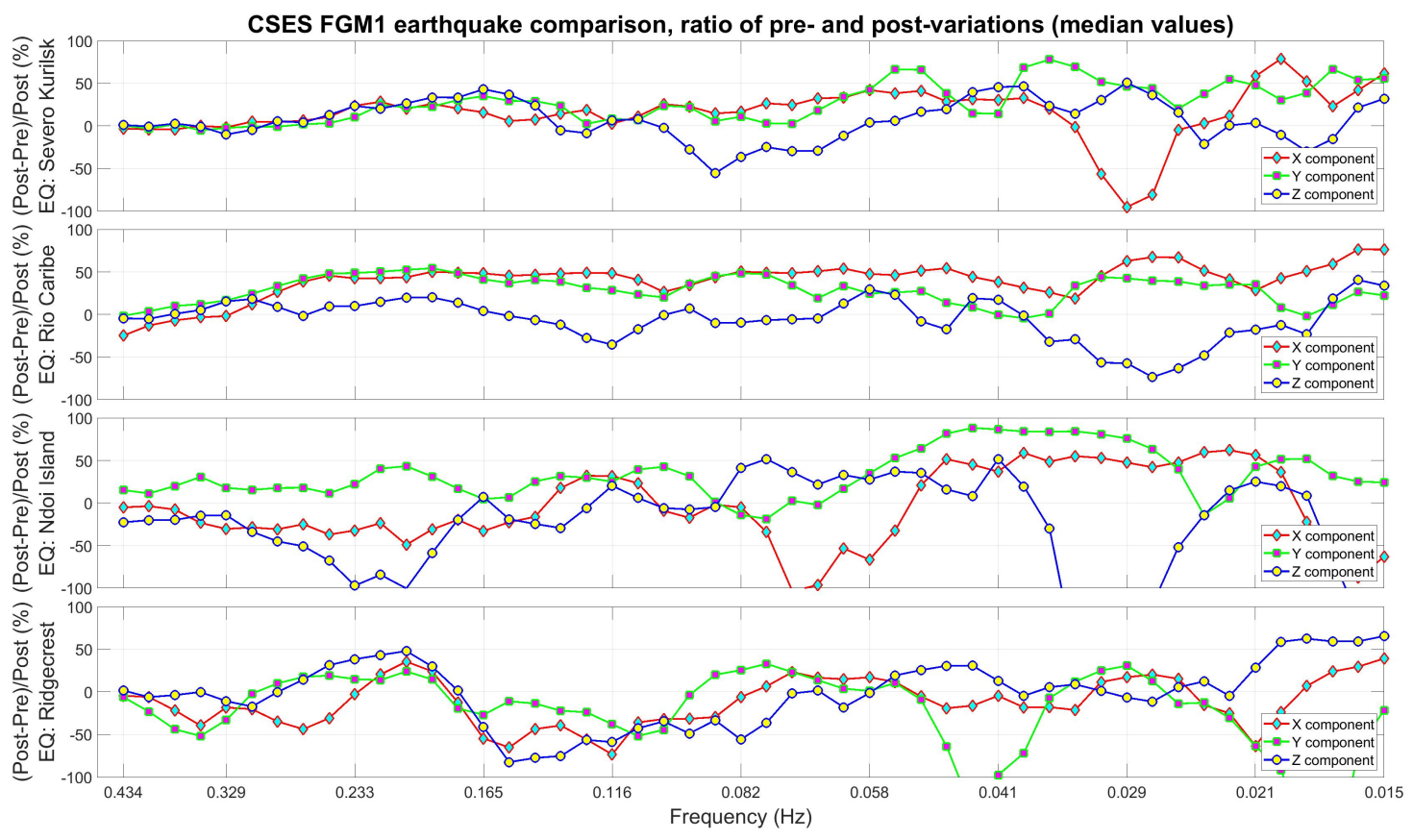

Figure 11. Relative changes based on median values of pre- and post-variations for the earthquakes M6.5 Severo-Kurilsk, M7.3 Rio Caribe, M8.2 Ndoi Island, and M7.1 Ridgecrest from CSES FGM1 magnetic field measurements. For Severo-Kurilsk (Figure 3), Rio Caribe (Figure 4), and Ridgecrest (Figure 6) the applicable range is from $0.434 \mathrm{~Hz}$ to $0.041 \mathrm{~Hz}$, for Ndoi Island (Figure 5) up to $0.082 \mathrm{~Hz}$, frequency bands below have too weak fluctuations. After an increase in the ratios to positive values, Severo-Kurilsk and Rio Caribe show enhancements mainly in the X-and Y-components along the frequency band, Ndoi Island is higher in the Y-component with oscillating behaviour. Ridgecrest shows a sinusoidal modulation of the ratios from higher to lower frequencies. For all events usually at least two (varying) components have a parallel moving pattern.

Author Contributions: The authors contributed in the following way: conceptualisation and software, C.S., H.U.E., M.Y.B., and K.S.; methodology, C.S., H.U.E., and M.Y.B.; validation (in terms of project specific scientific goals), W.M.; formal analysis, B.P.B., M.D., and M.Y.B.; investigation (expertise about ground based natural hazards issues), P.F.B. and M.S.; resources (in particular in the frame of CSES HPM), A.P.; data curation, X.S., J.W., B.C., B.Z., and A.P.; writing-original draft preparation, C.S. and H.U.E.; writing-review and editing, B.P.B.; visualisation, C.S. and H.U.E.; supervision, project administration, and funding acquisition, W.M. and R.L. All authors have read and agreed to the published version of the manuscript.

Funding: This research contract from C.S. was funded by Austrian Research Promotion Agency (FFG) in the frame of FFG project number 873688 (ASAP 15, Oriented Basic Research), short title "CDSM for CSES 2", under the two project leading participants (i) Space Research Institute (IWF), Austrian Academy of Sciences (OeAW), and (ii) Institute of Experimental Physics (IEP), Graz University of Technology (TUG). The Article Processing Costs (APC) were co-funded by Open Access (OA) Fonds, Austrian Academy of Sciences (OeAW).

Data Availability Statement: Publicly available datasets were analyzed in this study. This data can be found and accessed as stated in the section "Materials".

Acknowledgments: We kindly acknowledge the long-term administrative support from C. Grill, D. Hradecky, B. Flock, C. Muck, A. Scherr, and E. Tschachler in legal advice and business affairs. Support in computational issues and network services were mastered by F. Giner, U. NischelwitzerFennes, M. Pitterle, W. Voller, and M. Stachel, we highly appreciate their expertise and active assistance. R. Nakamura from the space plasma physics group and W. Baumjohann from the general management contributed with expert knowledge. We thank the ISGI involved national institutes and the INTERMAGNET network. We appreciate the excellent work of the Swarm and CSES teams who made these missions and instruments a success. Sincere thanks are given to them all! 
Conflicts of Interest: The authors declare no conflicts of interest. The funders had no role in the design of the study; in the collection, analyses, or interpretation of data; in the writing of the manuscript, or in the decision to publish the results.

$\begin{array}{ll}\text { Abbreviations } \\ \text { The following abbreviations are used in this manuscript: } \\ \text { AGW } & \text { Atmospheric Gravity Wave } \\ \text { ASI } & \text { Italian Space Agency } \\ \text { ASM } & \text { Absolute Scalar Magnetometer } \\ \text { AW } & \text { Acoustic Wave } \\ \text { CDF } & \text { Common Data Format } \\ \text { CDSM } & \text { Coupled Dark State Magnetometer } \\ \text { CNSA } & \text { China National Space Administration } \\ \text { CSES } & \text { China Seismo-Electromagnetic Satellite (Zhangheng-1) } \\ \text { Dst } & \text { Disturbance Storm Time Index } \\ \text { EQ } & \text { Earthquake } \\ \text { FGM } & \text { Fluxgate Magnetometer (FGM1 and FGM2 for CSES HPM) } \\ \text { GNSS } & \text { Global Navigation Satellite System } \\ \text { GPS } & \text { Global Positioning System } \\ \text { HDF5 } & \text { Hierarchical Data Format version 5 } \\ \text { HPM } & \text { High Precision Magnetometer } \\ \text { ISGI } & \text { International Service of Geomagnetic Indices } \\ \text { LAIC } & \text { Lithospheric Atmospheric Ionospheric Coupling } \\ \text { LEO } & \text { Low Earth Orbit } \\ \text { TEC } & \text { Total Electron Content } \\ \text { USGS } & \text { United States Geological Survey } \\ \text { UTC } & \text { Coordinated Universal Time } \\ \text { VFM } & \text { Vector Field Magnetometer } \\ \text { VLF/LF } & \text { Very Low Frequency / Low Frequency } \\ & \end{array}$

\section{References}

1. Elliott, J.R.; Walters, R.J.; Wright, T.J. The role of space-based observation in understanding and responding to active tectonics and earthquakes. Nat. Commun. 2016, 7, 13844. [CrossRef]

2. Shen, X.; Zhang, X.; Yuan, S.; Wang, L.; Cao, J.; Huang, J.; Zhu, X.; Picozzo, P.; Dai, J. The state-of-the-art of the China Seismo-Electromagnetic Satellite mission. Sci. China Technol. Sci. 2018, 61, 634-642. [CrossRef]

3. Zhou, B.; Yang, Y.; Zhang, Y.; Gou, X.; Cheng, B.; Wang, J.; Li, L. Magnetic field data processing methods of the China Seismo-Electromagnetic Satellite. Earth Planet. Phys. 2018, 2, 455-461. [CrossRef]

4. Pollinger, A.; Lammegger, R.; Magnes, W.; Hagen, C.; Ellmeier, M.; Jernej, I.; Leichtfried, M.; Kürbisch, C.; Maierhofer, R.; Wallner, R.; et al. Coupled dark state magnetometer for the China Seismo-Electromagnetic Satellite. Meas. Sci. Technol. 2018, $29,095103$. [CrossRef]

5. Pollinger, A.; Amtmann, C.; Betzler, A.; Cheng, B.; Ellmeier, M.; Hagen, C.; Jernej, I.; Lammegger, R.; Zhou, B.; Magnes, W. In-orbit results of the Coupled Dark State Magnetometer aboard the China Seismo-Electromagnetic Satellite. Geosci. Instrum. Methods Data Syst. 2020, 9, 275-291. [CrossRef]

6. Huang, J.; Shen, X.; Zhang, X.; Lu, H.; Tan, Q.; Wang, Q.; Yan, R.; Chu, W.; Yang, Y.; Liu, D.; et al. Application system and data description of the China Seismo-Electromagnetic Satellite. Earth Planet. Phys. 2018, 2, 444-454. [CrossRef]

7. Olsen, N.; Friis-Christensen, E.; Floberghagen, R.; Alken, P.; Beggan, C.D.; Chulliat, A.; Doornbos, E.; da Encarnação, J.T.; Hamilton, B.; Hulot, G.; et al. The Swarm Satellite Constellation Application and Research Facility (SCARF) and Swarm data products. Earth Planets Space 2013, 65, 1189-1200. [CrossRef]

8. Yang, Y.; Hulot, G.; Vigneron, P.; Shen, X.; Zhima, Z.; Zhou, B.; Magnes, W.; Olsen, N.; Tøffner-Clausen, L.; Huang, J.; et al. The CSES global geomagnetic field model (CGGM): An IGRF-type global geomagnetic field model based on data from the China Seismo-Electromagnetic Satellite. Earth Planets Space 2021, 73, 1-21. [CrossRef]

9. Zhang, X.; Wang, Y.; Boudjada, M.Y.; Liu, J.; Magnes, W.; Zhou, Y.; Du, X. Multi-Experiment Observations of Ionospheric Disturbances as Precursory Effects of the Indonesian Ms6.9 Earthquake on August 05, 2018. Remote Sens. 2020, $12,4050$. [CrossRef]

10. Boudjada, M.Y.; Galopeau, P.H.M.; Sawas, S.; Denisenko, V.; Schwingenschuh, K.; Lammer, H.; Eichelberger, H.U.; Magnes, W.; Besser, B. Low-altitude frequency-banded equatorial emissions observed below the electron cyclotron frequency. Ann. Geophys. 2020, 38, 765-774. [CrossRef] 
11. Ouzounov, D.; Pulinets, S.; Hattori, K.; Taylor, P. (Eds.) Pre Earthquake Processes a Multidisciplinary Approach to Earthquake Prediction Studies; Geophysical Monograph 234; American Geophysical Union: Washington, DC, USA; John Wiley and Sons, Inc.: Hoboken, NJ, USA, 2018; 365p. [CrossRef]

12. Simões, F.; Pfaff, R.; Berthelier, J.J.; Klenzing, J. A Review of Low Frequency Electromagnetic Wave Phenomena Related to Tropospheric-Ionospheric Coupling Mechanisms. Space Sci. Rev. 2012, 168, 551-593. [CrossRef]

13. Uyeda, S.; Hayakawa, M.; Nagao, T.; Molchanov, O.; Hattori, K.; Orihara, Y.; Gotoh, K.; Akinaga, Y.; Tanaka, H. Electric and magnetic phenomena observed before the volcano-seismic activity in 2000 in the Izu Island Region, Japan. Proc. Natl. Acad. Sci. USA 2002, 99, 7352-7355. [CrossRef]

14. Němec, F.; Santolík, O.; Parrot, M.; Berthelier, J.J. Spacecraft observations of electromagnetic perturbations connected with seismic activity. Geophys. Res. Lett. 2008, 35. [CrossRef]

15. De Santis, A.; Marchetti, D.; Pavón-Carrasco, F.J.; Cianchini, G.; Perrone, L.; Abbattista, C.; Alfonsi, L.; Amoruso, L.; Campuzano, S.A.; Carbone, M.; et al. Precursory worldwide signatures of earthquake occurrences on Swarm satellite data. Sci. Rep. 2019, 9, 20287. [CrossRef] [PubMed]

16. Rikitake, T. Earthquake precursors in Japan: Precursor time and detectability. Tectonophysics 1987, 136, 265-282. [CrossRef]

17. Marchetti, D.; De Santis, A.; Jin, S.; Campuzano, S.A.; Cianchini, G.; Piscini, A. Co-Seismic Magnetic Field Perturbations Detected by Swarm Three-Satellite Constellation. Remote Sens. 2020, 12, 1166. [CrossRef]

18. De Santis, A.; Marchetti, D.; Spogli, L.; Cianchini, G.; Pavón-Carrasco, F.J.; Franceschi, G.D.; Di Giovambattista, R.; Perrone, L.; Qamili, E.; Cesaroni, C.; et al. Magnetic Field and Electron Density Data Analysis from Swarm Satellites Searching for Ionospheric Effects by Great Earthquakes: 12 Case Studies from 2014 to 2016. Atmosphere 2019, 10, 371. [CrossRef]

19. Schwingenschuh, K.; Prattes, G.; Besser, B.P.; Močnik, K.; Stachel, M.; Aydogar, O.; Jernej, I.; Boudjada, M.Y.; Stangl, G.; Rozhnoi, A.; et al. The Graz seismo-electromagnetic VLF facility. Nat. Hazards Earth Syst. Sci. 2011, 11, 1121-1127. [CrossRef]

20. Biagi, P.F.; Colella, R.; Schiavulli, L.; Ermini, A.; Boudjada, M.; Eichelberger, H.; Schwingenschuh, K.; Katzis, K.; Contadakis, M.E.; Skeberis, C.; et al. The INFREP Network: Present Situation and Recent Results. Open J. Earthq. Res. 2019, 8, 101-115. [CrossRef]

21. Rozhnoi, A.; Solovieva, M.; Fedun, V.; Gallagher, P.; McCauley, J.; Boudjada, M.Y.; Shelyag, S.; Eichelberger, H.U. Strong influence of solar X-ray flares on low-frequency electromagnetic signals in middle latitudes. Ann. Geophys. 2019, 37, 843-850. [CrossRef]

22. Yang, S.S.; Asano, T.; Hayakawa, M. Abnormal Gravity Wave Activity in the Stratosphere Prior to the 2016 Kumamoto Earthquakes. J. Geophys. Res. (Space Phys.) 2019, 124, 1410-1425. [CrossRef]

23. Hines, C.O. Internal atmospheric gravity waves at ionospheric heights. Can. J. Phys. 1960, 38, 1441. [CrossRef]

24. Lambin, J.; Farges, T.; Lognonné, P. Acoustic waves generated from seismic surface waves: Propagation properties determined from Doppler sounding observations and normal-mode modelling. Geophys. J. Int. Geophys. Int. 2004, 158, 1067-1077. [CrossRef]

25. Hickey, M.P.; Schubert, G.; Walterscheid, R.L. Propagation of tsunami-driven gravity waves into the thermosphere and ionosphere. J. Geophys. Res. (Space Phys.) 2009, 114, A08304. [CrossRef]

26. Shults, K.; Astafyeva, E.; Adourian, S. Ionospheric detection and localization of volcano eruptions on the example of the April 2015 Calbuco events. J. Geophys. Res. (Space Phys.) 2016, 121, 10303-10315. [CrossRef]

27. Heki, K. Explosion energy of the 2004 eruption of the Asama Volcano, central Japan, inferred from ionospheric disturbances. Geophys. Res. Lett. 2006, 33, L14303. [CrossRef]

28. Zlotnicki, J.; Li, F.; Parrot, M. Ionospheric Disturbances Recorded by DEMETER Satellite over Active Volcanoes: From August 2004 to December 2010. Int. J. Geophys. 2013, 530865. [CrossRef]

29. Schirninger, C.; Schwingenschuh, K.; Eichelberger, H.; Mandl, B.; Pollinger, A.; Magnes, W.; Boudjada, M.Y.; Lammegger, R.; Delva, M.; Hagen, C.; et al. Magnetic field investigations of volcanic and seismic phenomena with the China Seismo-Electromagnetic Satellite (CSES). In Proceedings of the Magnetometer Workshop 2019, Stubenberg am See, Austria, 16-20 September 2019.

30. Schwingenschuh, K.; Magnes, W.; Shen, X.; Wang, J.; Cheng, B.; Pollinger, A.; Hagen, C.; Lammegger, R.; Ellmeier, M.; Schirninger, C.; et al. Satellite and ground-based magnetic field observations related to volcanic eruptions. In Proceedings of the EGU General Assembly, Online, 4-8 May 2020; [CrossRef]

31. Byrne, P.K. A comparison of inner Solar System volcanism. Nat. Astron. 2020, 4, 321-327. [CrossRef]

32. Gudmundsson, M.T.; Jónsdóttir, K.; Hooper, A.; Holohan, E.P.; Halldórsson, S.A.; Ófeigsson, B.G.; Cesca, S.; Vogfjörd, K.S.; Sigmundsson, F.; Högnadóttir, T.; et al. Gradual caldera collapse at Bárdarbunga volcano, Iceland, regulated by lateral magma outflow. Science 2016, 353. [CrossRef] [PubMed]

33. Kundu, B.; Senapati, B.; Matsushita, A.; Heki, K. Atmospheric wave energy of the 2020 August 4 explosion in Beirut, Lebanon, from ionospheric disturbances. Sci. Rep. 2021, 11, 2793. [CrossRef] [PubMed]

34. Schneider, F.M.; Fuchs, F.; Kolínský, P.; Caffagni, E.; Serafin, S.; Dorninger, M.; Bokelmann, G.; AlpArray Working Group. Seismo-acoustic signals of the Baumgarten (Austria) gas explosion detected by the AlpArray seismic network. Earth Planet. Sci. Lett. 2018, 502, 104-114. [CrossRef]

35. Lin, C.C.H.; Shen, M.H.; Chou, M.Y.; Chen, C.H.; Yue, J.; Chen, P.C.; Matsumura, M. Concentric traveling ionospheric disturbances triggered by the launch of a SpaceX Falcon 9 rocket. Geophys. Res. Lett. 2017, 44, 7578-7586. [CrossRef]

36. Wessel, P.; Smith, W.H.F.; Scharroo, R.; Luis, J.; Wobbe, F. Generic Mapping Tools: Improved Version Released. EOS Trans. Am. Geophys. Union 2013, 94, 409-410. [CrossRef] 